\title{
The Deubiquitinating Enzyme USP-46 Negatively Regulates the Degradation of Glutamate Receptors to Control Their Abundance in the Ventral Nerve Cord of Caenorhabditis elegans
}

\author{
Jennifer R. Kowalski, Caroline L. Dahlberg, and Peter Juo \\ Department of Molecular Physiology and Pharmacology, Tufts University School of Medicine, Boston, Massachusetts 02111
}

\begin{abstract}
Ubiquitin-mediated endocytosis and post-endocytic trafficking of glutamate receptors control their synaptic abundance and are implicated in modulating synaptic strength. Ubiquitination is a reversible modification, but the identities and specific functions of deubiquitinating enzymes in the nervous system are lacking. Here, we show that the deubiquitinating enzyme ubiquitin-specific protease-46 (USP-46) regulates the abundance of the glutamate receptor GLR-1 in the ventral nerve cord of Caenorhabditis elegans. Mutants lacking usp-46 have decreased GLR-1 in the ventral nerve cord and corresponding defects in GLR-1-dependent behaviors. The amount of ubiquitinated GLR-1 is increased in usp-46 mutants. Mutations that block GLR-1 ubiquitination or receptor degradation in the multivesicular body/lysosome prevent the decrease in GLR-1 observed in usp-46 mutants. These data support a model in which USP-46 promotes GLR-1 abundance at synapses by deubiquitinating GLR-1 and preventing its degradation in the lysosome. This work suggests that the balance between the addition and removal of ubiquitin is important for glutamate receptor trafficking.
\end{abstract}

\section{Introduction}

Regulation of synaptic strength is critical for nervous system function and constitutes the molecular basis for learning and memory. Changes in the abundance of postsynaptic AMPA-type glutamate receptors (AMPARs) via activity-dependent regulation of receptor exocytosis and endocytosis can alter synaptic strength and are major cellular mechanisms for long-term potentiation and long-term depression (Shepherd and Huganir, 2007). After endocytosis, AMPARs can be sorted into multi-vesicular bodies (MVBs) for degradation in the lysosome or into recycling endosomes for delivery back to the postsynaptic membrane (Ehlers, 2000; Lin et al., 2000), but the mechanisms involved are poorly understood.

Ubiquitin has emerged as a key regulator of synapse development and synaptic plasticity (Jiang et al., 1998; Speese et al., 2003; Zhao et al., 2003; Yi and Ehlers, 2007). Ubiquitination of membrane proteins is a highly conserved mechanism that is used to

\footnotetext{
Received Sept. 10, 2010; revised 0ct. 23, 2010; accepted Nov. 1, 2010.

This research was supported by National Institutes of Health (NIH) Grant NS 59953 (P.J.), a Basil O'Connor March of Dimes Scholar Award (P.J.), and the Tufts Center for Neuroscience Research (NIH Grant P30 NS047243). J.R.K. and C.L.D. were supported by the Training in Education and Critical Research Skills postdoctoral program (NIH Grant 5K12GM074869). We thank Josh Kaplan, Michele Jacob, Larry Feig, Victor Hatini, Lars Dreier, and members of the Juo laboratory for advice and comments on this manuscript. We thank the following for strains and reagents: Josh Kaplan, Villu Maricq, Lars Dreier, Jeremy Dittman, Gary Ruvkun, Brent Cochran, Jason McEwen, Derek Sieburth, Denise Chun, Hidde Ploegh, the Caenorhabditis Genetics Center, and the C. elegans Gene Knockout Consortium.

Correspondence should be addressed to Dr. Peter Juo, Department of Molecular Physiology and Pharmacology, Tufts University School of Medicine, 150 Harrison Avenue, Boston, MA 02111. E-mail: peter.juo@tufts.edu.

J. R. Kowalski's present address: Department of Biological Sciences, Butler University, 4600 Sunset Avenue, Indianapolis, IN 46208.

DOI:10.1523/JNEUROSCI.4765-10.2011

Copyright $\odot 2011$ the authors $\quad 0270-6474 / 11 / 311341-14 \$ 15.00 / 0$
}

mark proteins at the cell surface for endocytosis and to sort proteins in the early endosome into the MVB/lysosome pathway for degradation (Hicke and Dunn, 2003). Indeed, glutamate receptor (GluR) trafficking in both invertebrates and mammals is controlled by ubiquitination (Burbea et al., 2002; Colledge et al., 2003; Patrick et al., 2003; Juo and Kaplan, 2004; van Roessel et al., 2004; Dreier et al., 2005; Kato et al., 2005; Schaefer and Rongo, 2006; Jurd et al., 2008; Park et al., 2009). Ubiquitin is attached to specific substrates by a large family of E3 ubiquitin ligases (Hicke and Dunn, 2003). However, ubiquitination is reversible, and removal of ubiquitin is accomplished by a less well understood family of proteases called deubiquitinating enzymes (DUBs) (Nijman et al., 2005).

The need for dynamic control of synaptic protein abundance and the reversible nature of ubiquitination suggest that the balance between ubiquitination and deubiquitination is critical for proper synapse function; however, only a few synaptic DUBs have been described. One important function of DUBs is to act in a target-specific manner to counter the action of ubiquitin ligases. Genetic studies in Drosophila demonstrated that the balance of activity between the DUB Fat facets and the ubiquitin ligase Highwire is critical for synapse function (DiAntonio et al., 2001). Mammalian Fat facets Usp9x/FAM specifically regulates the deubiquitination of the presynaptic vesicle endocytic protein epsin/liquid facets in an activity-dependent manner (Chen et al., 2003). Other DUBs function more generally to maintain the cellular pool of free ubiquitin monomers (Song and Rape, 2008). Disruption of DUBs involved in ubiquitin homeostasis, such as Ap-Uch in Aplysia and ubiquitin carboxyl-terminal hydrolase L1 (Uch-L1) and ubiquitin-specific protease 14 (Usp14) in mam- 
mals, result in defects in long-term facilitation (Hegde et al., 1997) and in synapse structure and function (Wilson et al., 2002; Gong et al., 2006; Cartier et al., 2009; Chen et al., 2010). Given that the majority of DUBs are expected to counter the actions of ubiquitin ligases by deubiquitinating specific target proteins, much remains to be learned regarding the identities of DUBs and their substrates in the nervous system.

Here we describe a novel and specific role for the deubiquitinating enzyme USP-46 and show that it controls the abundance of GLR-1 glutamate receptors in Caenorhabditis elegans.

\section{Materials and Methods}

Strains. The following strains were used in this study: N2 Bristol, nuIs24 (Pglr-1::GLR-1::GFP), nuIs25 (Pglr-1::GLR-1::GFP), nuIs125 (Pglr-1:: Synaptobrevin::GFP), nuIs108 [Pglr-1::GLR-1(4KR)::GFP], nuIs145 [Pglr-1::vps4(DN)], lin-35(n745);eri-1(mg366), usp-46(ok2232), unc11(e47), glr-1(n2461), pzEx100 [Pglr-1::usp-46(wt)], pzEx93 (Pglr-1:: mCherry::USP-46), pzEx85 (Pusp-46::GFP), pzEx99 (Pusp-46::NLS::GFP), pzEx96 (Pglr-1::dsRED), nuEx1004 (Pglr-1::MAGI-1::YFP), nuEx993 (Pglr-1::LIN-10::GFP), pzEx132 (Pnmr-1::YFP::SOL-1), pzIs12 (Pglr-1:: HA::GLR-1::GFP), pzEx133 (Pglr-1::Venus::KDEL), nuIs80 [Pglr-1:: GLR-1(A/T)::YFP], and pzEx135 (Pglr-1::Venus::RAB-5). All strains were maintained at $20^{\circ} \mathrm{C}$ as described previously (Brenner, 1974).

Identification of R1OE11.3 as USP-46. An alignment of the amino acid sequences of R10E11.3, human USP-46, and human USP-12 proteins was performed using Clustal X software. Thirty-nine residues differ between human USP-12 and USP-46. Nine of these 39 residues in R10E11.3 are identical to mammalian USP-12, 13 residues are identical to USP-46, and 17 residues are not identical to either homolog. Because a greater number of homologous residues was found between R10E11.3 and USP-46, we named the R1OE11.3 gene usp-46. Additional R10E11.3 homologs exist in other vertebrate and invertebrate species, including Xenopus laevis, Drosophila melanogaster, and Danio rerio, as well as in yeast (data not shown) (Hansen-Hagge et al., 1998), indicating the high conservation of this DUB across phylogeny.

Constructs, transgenes, and germ-line transformation. Plasmids were generated using standard techniques, and details are available on request. Pglr-1::usp-46(wt) (FJ\#1) was made by subcloning the $1281 \mathrm{nt}$ open reading frame of R10E11.3a into the pV6 glr-1 expression vector (KP\#1008). To create the Pglr-1::usp-46(C>A) mutant in pV6 (FJ\#2), Quickchange sitedirected mutagenesis with Pfu Ultra DNA polymerase (Stratagene) was used to change the cysteine at amino acid 36 in USP-46 (plasmid FJ\#1) to alanine. Pglr-1::mCherry::USP-46 (FJ\#3) was generated by subcloning the mCherry sequence from plasmid KP\#1272 downstream of and in-frame with the USP-46 start codon in FJ\#1 using a NotI restriction site engineered into the $5^{\prime}$ end of the $u s p-46 \mathrm{cDNA}$. Glutathione $S$-transferase (GST)-tagged USP-46 or USP-46(C>A) were generated by PCR subcloning usp-46 and usp$46(C>A)$ from $\mathrm{FJ} \# 1$ and FJ\#2 into pGEX-4T1 to create pGEX-4T-USP46(FJ\#58) and pGEX-4T-USP-46(C>A) (FJ\#59), respectively. pSK-USP-46 (FJ\#60) was generated by subcloning $u s p-46$ from FJ\#1 into pSK. Standard techniques were used to isolate transgenic strains by microinjection of these plasmids (10 ng/ $\mu \mathrm{l}$ for $\mathrm{FJ} \# 1$ and $\mathrm{FJ} \# 2 ; 25 \mathrm{ng} / \mu \mathrm{l}$ for FJ\#3) along with the

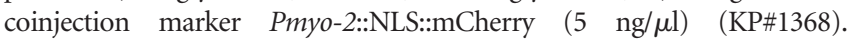
Pnmr-1::YFP::SOL-1 (pYZ167; gift from V. Maricq, University of Utah, Salt Lake City, UT), Pglr-1:: HA::GLR-1::GFP (pWR6; gift from V. Maricq), $P g l r-1::$ MAGI-1::YFP, and $P g l r-1::$ LIN-10::GFP were each injected at $25 \mathrm{ng} /$ $\mu$ l. Pglr-1::Venus::KDEL (gift from J. Kaplan, Massachusetts General Hospital, Boston, MA) was injected at $10 \mathrm{ng} / \mu \mathrm{l}$. Pusp-46::GFP (FJ\#7) was created by subcloning $2.0 \mathrm{~kb}$ of the $5^{\prime}$ untranslated region of R10E11.3 upstream of the start codon into pPD49.26 expressing green fluorescent protein (GFP). Pusp-46::NLS::GFP (FJ\#8) was created by subcloning $2.0 \mathrm{~kb}$ of the $5^{\prime}$ untranslated region of R10E11.3 upstream of the start codon into pPD95.67. pzEx85 (FJ\#7) was injected at $25 \mathrm{ng} / \mu \mathrm{l}$ along with the coinjection marker Pmyo-2::NLS::mCherry. pzEx99 (FJ\#8) was injected at $50 \mathrm{ng} / \mu \mathrm{l}$. pzEx96 (Pglr-1::dsRED) (KP\#889; gift from J. Kaplan) was injected at $25 \mathrm{ng} / \mu \mathrm{l}$. pzEx135 (Pglr-1::Venus::RAB-5) was injected at $1 \mathrm{ng} / \mu \mathrm{l}$ along with the coinjection marker Pttx-3::GFP

RNA interference. RNA interference (RNAi) screening was performed in the GLR-1::GFP-expressing RNAi-enhanced strain nuIs25 lin- 35(n745);eri-1 (mg366) (kindly provided by L. Dreier, University of California, Los Angeles, Los Angeles, CA) (Wang et al., 2005). RNAi clones targeting genes encoding DUBs (identified by homology) were cherrypicked from a genome-wide library consisting of Escherichia coli carrying RNAi constructs in the T7-tailed L4440 vector (Kamath et al., 2003; Rual et al., 2004). Bacteria were maintained in the presence of $50 \mu \mathrm{g} / \mathrm{ml} \mathrm{am}$ picillin and $15 \mu \mathrm{g} / \mathrm{ml}$ tetracycline for plasmid selection (Kamath et al., 2003). For GLR-1::GFP imaging experiments, two-generation RNAi was performed as follows: $3 \mathrm{ml}$ overnight cultures of bacteria carrying an RNAi plasmid targeting either R10E11.3 or lin-35 (control) were grown in Luria broth containing $50 \mu \mathrm{g} / \mathrm{ml}$ ampicillin. One hundred fifty microliters of these cultures were spotted onto $35 \mathrm{~mm}$ nematode growth medium (NGM) agar plates containing $50 \mu \mathrm{g} / \mathrm{ml}$ ampicillin and $5 \mathrm{~mm}$ isopropyl- $\beta$-D-thiogalactopyranoside (IPTG). Plates were dried open in a chemical hood for $2 \mathrm{~h}$ and then closed overnight at room temperature. Three larval stage 4 (L4) animals per strain were placed on each plate and grown at $20^{\circ} \mathrm{C}$ for $4 \mathrm{~d}$ (one-generation RNAi). Three first-generation L4 animals were transferred to freshly made RNAi plates and grown 4 additional days at $20^{\circ} \mathrm{C}$ (two-generation RNAi). Second-generation L4 worms picked from these plates were imaged as described below.

Fluorescence imaging. All imaging experiments were performed using a Carl Zeiss Axiovert M1 microscope with a $100 \times$ Plan Apochromat (1.4 numerical aperture) objective equipped with GFP and red fluorescent protein filters. L4 animals were immobilized with $30 \mathrm{mg} / \mathrm{ml} \mathrm{2,3-}$ butanedione monoxamine (Sigma-Aldrich) for 5-6 min before imaging. Images were captured with an Orca-ER CCD camera (Hamamatsu) using MetaMorph (version 7.1) software (Molecular Devices).

For quantitative analyses of fluorescent ventral nerve cord (VNC) puncta, maximum intensity projections of $Z$-series stacks $(1 \mu \mathrm{m}$ total depth) were made. Exposure settings and gain were set to fill the 12-bit dynamic range without saturation and were identical for all images taken of a given fluorescent marker. All images were taken of the anterior portion of the ventral nerve cord, just posterior to the RIG neuronal cell bodies. Line scans of ventral cord puncta were generated using MetaMorph (version 6.0). Line-scan data were analyzed with Igor Pro (version 5) (Wavemetrics) using custom-written software as described previously (Burbea et al., 2002). Arc lamp output was normalized by measuring the intensities of $0.5 \mu \mathrm{m}$ FluoSphere beads (Invitrogen) for each imaging day. Puncta intensities were normalized to the average bead intensity for the corresponding day. These bead-corrected intensities were normalized to wild-type controls. Puncta widths were calculated by measuring the width of each punctum at half the maximal peak fluorescence intensity. Puncta densities were determined by quantifying the average number of puncta per $10 \mu \mathrm{m}$ of the ventral nerve cord.

To quantify the amount of GLR-1::GFP in neuronal cell bodies, images were taken of PVC cell bodies, and maximum intensity projections were generated from $Z$-series stacks $(2 \mu \mathrm{m}$ total depth) as described above. The average pixel intensities of three separate regions of each cell body were measured using MetaMorph (version 7.1) software.

Surface labeling of HA::GLR-1::GFP was performed as described previously (Zheng et al., 2004; Wang et al., 2008a). Briefly, the pseudocoelom of young adult transgenic animals were injected with antihemagglutinin (HA)-Alexa Fluor 594 antibodies (16B12) (Invitrogen) diluted $20 \times$ in dilution buffer (10 mm HEPES, pH 7.7, $50 \mathrm{~mm} \mathrm{NaCl}, 10 \%$ glycerol, and $1 \mathrm{mg} / \mathrm{ml} \mathrm{BSA}$ ), recovered for $2-3 \mathrm{~h}$ at $20^{\circ} \mathrm{C}$, imaged, and quantified as described above.

For all imaging quantification, average \pm SEM values (normalized to wild-type) are reported, and statistical significance was determined using the Student's $t$ test.

Real-time PCR. Total RNA was isolated from mixed-stage populations of wild-type and $u s p-46$ mutant animals using an RNeasy Fibrous Tissue Mini kit (Qiagen). Two independent RNA preparations were made for each genotype. cDNA was synthesized from this RNA using Superscript III Reverse Transcriptase (Invitrogen). Real-time PCR was performed using the Brilliant SYBR Green QPCR Master Mix, including SureStart Taq polymerase (Stratagene). Reactions were run on a Stratagene MX3000P real-time PCR machine (Tufts Center for Neuroscience Research). Standard curves were used to calculate the relative amount of $g l r-1$ mRNA in each sample, and this was normalized to the relative 
amount of act-1 actin mRNA. The glr-1/act-1 ratio in wild-type animals was set to 1 in the figure shown. Significant differences were determined using the Student's $t$ test ( $n=6$ replicates per genotype).

Subcellular fractionations, immunoprecipitations, and Western blots. Membrane fractions were isolated from mixed-stage populations of wild-type and usp-46 mutant worms expressing GLR-1::GFP (nuIs25) as follows. Lysates were prepared essentially as described (Cheeseman and Desai, 2005). Briefly, worms were washed off plates in $100 \mathrm{~mm} \mathrm{NaCl}$, isolated by sucrose gradient centrifugation, and resuspended in freezing buffer (50 mм HEPES, pH 7.4, 1 mм EGTA, 1 mм $\mathrm{MgCl}_{2}, 100 \mathrm{~mm} \mathrm{KCl,}$ and $10 \%$ glycerol) plus $1 \mathrm{~mm}$ PMSF and $10 \mathrm{~mm} N$-ethylmaleimide (NEM). Worm suspensions were dropped into liquid nitrogen, and the recovered frozen pellets were ground using a chilled mortar and pestle. Lysates were made by resuspending the ground worm powder in buffer $\mathrm{A}$ (50 mм HEPES, pH 7.7, $50 \mathrm{~mm}$ potassium acetate, $2 \mathrm{~mm}$ magnesium acetate, $250 \mathrm{~mm}$ sucrose, and $1 \mathrm{~mm}$ EDTA) plus protease inhibitors (10 $\mu \mathrm{g} / \mathrm{ml}$ leupeptin, $5 \mu \mathrm{g} / \mathrm{ml}$ chymostatin, $3 \mu \mathrm{g} / \mathrm{ml}$ elastin, $1 \mu \mathrm{g} / \mathrm{ml}$ pepstatin A, and $1 \mathrm{~mm}$ PMSF) and $10 \mathrm{~mm}$ NEM, followed by sonication. Membranes were isolated by spinning the clarified lysates at 55,000 rpm in a Beckman Ti 60 rotor, followed by resuspension in buffer A plus protease inhibitors, NEM, and 7 mM $\beta$-mercaptoethanol (Burbea et al., 2002).

Immunoprecipitation (IP) experiments were performed as described previously (Burbea et al., 2002). Briefly, membranes were solubilized in 1 vol of SDS buffer ( 50 mM Tris-HCl, pH 8.5, 1\% SDS, and 2 mm DTT) and then diluted with $5 \mathrm{vol}$ of $50 \mathrm{~mm}$ HEPES, $\mathrm{pH} 7.7,250 \mathrm{~mm} \mathrm{NaCl}$, and $1 \%$ NP-40 plus protease inhibitors. GLR-1::GFP was immunoprecipitated with anti-GFP polyclonal antibodies (gift from J. Kaplan) and Protein A and Protein G Sepharose beads (GE Healthcare) at $4^{\circ} \mathrm{C}$ overnight (first IP). Washes were performed using $50 \mathrm{~mm}$ HEPES, pH 7.7, $150 \mathrm{~mm} \mathrm{NaCl}$, $1 \%$ NP-40, and GLR-1::GFP was eluted by incubation in SDS buffer twice at $95^{\circ} \mathrm{C}$ for $5 \mathrm{~min}$ per elution. Eluates were pooled and diluted with $5 \mathrm{vol}$ of $50 \mathrm{~mm}$ Tris, pH 7.6, $10 \mathrm{~mm}$ magnesium acetate, $1 \% \mathrm{NP}-40$, and $0.1 \mathrm{mg} / \mathrm{ml} \mathrm{IgG-free} \mathrm{BSA} \mathrm{(Sigma-Aldrich)} \mathrm{plus} \mathrm{protease} \mathrm{inhibitors.}$ Ubiquitin-conjugated GLR-1::GFP then was immunoprecipitated from the diluted eluate using anti-ubiquitin polyclonal antibodies (gift from J. Kaplan) and Protein A and Protein G Sepharose beads for $3 \mathrm{~h}$ at $4^{\circ} \mathrm{C}$ (second IP). Beads were washed in Tris-magnesium acetate-NP-40 buffer and eluted in SDS sample buffer (125 mM Tris, pH 6.8, 20\% glycerol, 5\% SDS, and $200 \mathrm{~mm}$ DTT). Total GLR-1::GFP from the first IP and ubiquitin-GLR-1::GFP conjugates from the second IP were analyzed by Western blot with either monoclonal anti-GFP antibodies (JL-8; Clonetech) and/or monoclonal anti-ubiquitin antibodies (P4D1; Covance), followed by horseradish peroxidase-conjugated anti-mouse secondary antibodies (GE Healthcare) and detected with Pierce Super Signal chemiluminescence solution using a UVP imager. Integrated band intensities were calculated using Adobe Photoshop, and the relative ratios of ubiquitinated GLR-1::GFP/total GLR-1::GFP were determined. Three independent membrane preparations for each strain were made and tested in IP experiments. For anti-ubiquitin blots, boxes were drawn around the entire area of ubiquitin-GLR-1 conjugates. To confirm that the bands observed on the anti-ubiquitin blot were ubiquitinated GLR-1, the double IP protocol was performed as described above on membranes from nuIs24 GLR-1::GFP-expressing animals with the following modification: anti-ubiquitin polyclonal antibodies were preincubated with 2 $\mathrm{mg} / \mathrm{ml}$ free ubiquitin (Sigma-Aldrich) or $2 \mathrm{mg} / \mathrm{ml}$ IgG-free BSA (SigmaAldrich) for $1 \mathrm{~h}$ at $4^{\circ} \mathrm{C}$, and excess $(2 \mathrm{mg} / \mathrm{ml})$ free ubiquitin or IgG-free BSA was also included in the second IP.

Total GLR-1::GFP protein levels were determined by Western blot analysis of total worm lysates prepared from mixed-stage populations of wild-type and usp-46 mutant worms expressing GLR-1::GFP (nuIs25). Lysates were made by resuspending worms in SDS sample buffer followed by a brief sonication. After electrophoresis and transfer, nitrocellulose membranes were cut in half. The upper half of the membrane was probed with monoclonal anti-GFP antibodies (L-8; Covance) and the lower half with polyclonal anti-tubulin antibodies (Abcam) for normalization of GLR-1 levels. Blots were further processed and detected as described above. Quantification of integrated band intensities was performed using Adobe Photoshop, and the ratios of GLR-1::GFP/tubulin were determined for each sample. Four independent lysates for each strain were made and analyzed by Western blot.

Endoglycosidase $\mathrm{H}$ (Endo $\mathrm{H}$ ) assays were performed as described previously (Grunwald and Kaplan, 2003). Briefly, membrane fractions were isolated and solubilized in SDS buffer as described above. Solubilized membranes were diluted in 5 vol of Endo $\mathrm{H}$ (New England Biolabs buffer G5) or peptide $N$-glycosidase F (PNGase F) (New England Biolabs buffer G7) assay buffer (supplemented with 1\% NP-40, $14 \mathrm{~mm} \beta$-mercaptoethanol, $1 \mathrm{~mm}$ PMSF, and protease inhibitors) and digested with Endo H or PNGase $\mathrm{F}$ enzyme for $2-3 \mathrm{~h}$ in a $37^{\circ} \mathrm{C}$ water bath. Endo $\mathrm{H}$ digestion only removes the simple carbohydrate modifications added in the endoplasmic reticulum (ER), whereas PNGase F digestion removes all glycosylation. Proteins were precipitated by adding $1 \mathrm{vol}$ of cold 20\% TCA, washed with acetone, and resuspended in sample buffer. Samples were analyzed by Western blot using GFP antibodies (JL-8; Clontech) and quantitated using an UVP gel imager and Adobe Photoshop. Three independent experiments were performed and analyzed. Percentage Endo H-sensitive GLR-1::GFP was calculated according to the following equation: \%Endo $\mathrm{H}-\mathrm{S}=[($ Endo $\mathrm{H}-\mathrm{S}) /($ Endo $\mathrm{H}-\mathrm{R}$ + Endo H-S) ${ }^{*}$ 100, where Endo H-S indicates Endo H-sensitive and Endo $\mathrm{H}-\mathrm{R}$ indicates Endo H-resistant. The average percentage \pm SEM Endo H-S for each strain is shown.

In vitro binding and deubiquitination assays. For purification of recombinant proteins, GST and GST fusions were expressed in DH5 $\alpha$ cells. All cultures were grown to log phase and induced with $0.1 \mathrm{~mm}$ IPTG. GST and GST-GLR-1C were induced at $37^{\circ} \mathrm{C}$ for $2.5 \mathrm{~h}$. After isolation on glutathione Sepharose beads, the proteins were eluted with $10 \mathrm{~mm}$ glutathione in buffer B (20 mm Tris, pH 7.5, $100 \mathrm{~mm} \mathrm{NaCl}$, and $1 \mathrm{~mm}$ DTT) and were dialyzed against buffer B. GST-USP-46 and GST-USP$46(\mathrm{C}>\mathrm{A})$ were expressed at $16^{\circ} \mathrm{C}$ for $20 \mathrm{~h}$. GST fusion proteins were either isolated on glutathione Sepharose beads immediately before use or were eluted from the beads with $10 \mathrm{~mm}$ glutathione and stored at $-80^{\circ} \mathrm{C}$.

For in vitro binding assays, ${ }^{35} \mathrm{~S}$-labeled MAGI-1 [consisting of the last three PDZ (postsynaptic density-95/Discs large/zona occludens-1) domains] and USP-46 were expressed from pBlueScript plasmids using TnT Coupled Reticulocyte Lysate System (Promega). After protein expression, GST or GST-GLR-1C terminus was incubated with the reticulocyte lysate for $2.5 \mathrm{~h}$ at $4^{\circ} \mathrm{C}$ in $500 \mu$ l of buffer C (25 mM HEPES, pH 7.8, $150 \mathrm{~mm} \mathrm{NaCl}$, and $1 \mathrm{~mm} \mathrm{DTT)}$ and $2 \mu \mathrm{g} / \mathrm{ml}$ PMSF. The reaction was incubated with glutathione resin for $1 \mathrm{~h}$ at $4^{\circ} \mathrm{C}$. The resin was washed four times with buffer C, resuspended in SDS buffer, and analyzed by SDSPAGE, Coomassie staining, and fluorography.

For binding assays between recombinant USP-46 and GLR-1::GFP, GST-USP-46 or GST-USP-46(C>A) was purified from bacteria and incubated with GLR-1::GFP-containing worm membrane fractions at $4^{\circ} \mathrm{C}$ overnight. GLR-1::GFP was immunoprecipitated with anti-GFP polyclonal antibodies and washed several times in buffer containing 50 mM HEPES, pH 7.7, $150 \mathrm{~mm} \mathrm{NaCl}$, and 1\% NP-40 or 50 mM HEPES, pH 7.7, $250 \mathrm{~mm} \mathrm{NaCl}$, and 1\% NP-40, before analysis by SDS-PAGE and Western blotting with anti-GFP (JL-8; Clontech) or anti-GST (Covance) antibodies. The reciprocal binding experiment was performed in a similar manner, except glutathione Sepharose beads were used to pull down GST, GST-USP-46, or GST-USP-46(C>A) that had been incubated with GLR-1::GFP membranes overnight at $4^{\circ} \mathrm{C}$.

For the in vitro DUB assay, GLR-1::GFP was immunoprecipitated from worm membrane fractions as described above and incubated with $500 \mathrm{ng}$ of recombinant GST-USP-46 or GST-USP-46(C>A) in DUB reaction buffer (20 mм HEPES-KOH, pH 7.8, $20 \mathrm{~mm} \mathrm{NaCl}, 0.1 \mathrm{mg} / \mathrm{ml}$ ovalbumin, $0.5 \mathrm{~mm}$ EDTA, and $10 \mathrm{~mm}$ DTT) for $30 \mathrm{~min}$ at $37^{\circ} \mathrm{C}$ as described (Kee et al., 2010). Samples were washed with buffer containing 50 mм HEPES, pH 7.7, $150 \mathrm{~mm} \mathrm{NaCl}$, and 1\% NP-40 before the elution step and second IP with anti-Ubiquitin antibody as described above. The relative amounts of ubiquitinated GLR-1::GFP was normalized to the total GLR-1::GFP in the first IP.

For labeling with an HA-tagged Ubiquitin vinyl methyl ester probe (HA-Ub-VME), 5-10 $\mu \mathrm{M}$ recombinant protein was incubated with $1 \mu \mathrm{g}$ of HA-Ub-VME (gift from Hidde Ploegh, Whitehead Institute for Biomedical Research, Cambridge, MA) in labeling buffer (20 mM Tris, $\mathrm{pH}$ $8.0,150 \mathrm{~mm} \mathrm{NaCl}$, and $1 \mathrm{~mm}$ DTT) for less than $1 \mathrm{~min}$ at room temperature (final reaction volume was $25 \mu \mathrm{l}$ ). Longer incubation times at $37^{\circ} \mathrm{C}$ 
did not improve labeling of either USP-46 or UCH-L3. Reactions were stopped with the addition of SDS sample buffer and were analyzed by SDS-PAGE, Coomassie staining, and Western blotting with anti-HA antibodies (Roche).

Behavioral assays. Nose touch assays were performed as described previously (Kaplan and Horvitz, 1993). Briefly, young adult hermaphrodites were placed on NGM agar plates containing a thin lawn of OP50 E. coli and then assayed for responsiveness to light contact on the nose with an eyelash. Ten touches were scored for each animal, and the average \pm SEM percentage of responses was determined for each genotype. Spontaneous locomotion of young adult hermaphrodites was analyzed as previously described (Juo et al., 2007). Briefly, individual worms were transferred using halocarbon oil to an NGM agar plate without food. Animals were allowed to equilibrate on the plate for $2 \mathrm{~min}$. The number of times forward-moving animals reversed direction was counted over a period of 5 $\mathrm{min}$. The average \pm SEM number of reversals per minute was calculated for each genotype. For both assays, statistical differences between genotypes were determined using the Student's $t$ test, and all behavioral assays were performed by an experimenter unaware of the genotypes of the animals being tested.

\section{Results}

USP-46 positively regulates GLR-1 abundance in the ventral nerve cord The genetic model organism C. elegans has been used to identify and characterize genes involved in regulating glutamate receptor trafficking. The $C$. elegans genome encodes two NMDA and eight non-NMDA receptor subunits (Brockie et al., 2001a). GLR-1 is a non-NMDA receptor subunit that is most similar to mammalian AMPA receptors by sequence homology (Hart et al., 1995; Maricq et al., 1995; Brockie et al., 2001a). GLR-1 is expressed in ventral cord interneurons and is localized to sensory-interneuron and interneuron-interneuron synapses in which it is required for several glutamatedependent behaviors (Hart et al., 1995; Maricq et al., 1995; Rongo et al., 1998; Zheng et al., 1999; Burbea et al., 2002). Previous studies have shown that ubiquitin is directly conjugated to GLR- 1 and provides a signal for its endocytosis and subsequent degradation in the MVB/lysosome pathway (Burbea et al., 2002; Chun et al., 2008). Several ubiquitin ligases that regulate the synaptic abundance of GLR-1 receptors have been identified in C. elegans (Juo and Kaplan, 2004; Dreier et al., 2005; Schaefer and Rongo, 2006; Park et al., 2009). Because these ligases have not been shown to directly ubiquitinate GLR-1, it remains possible that they function by ubiquitinating other proteins important for regulating GLR-1 abundance, as was shown in some of these studies
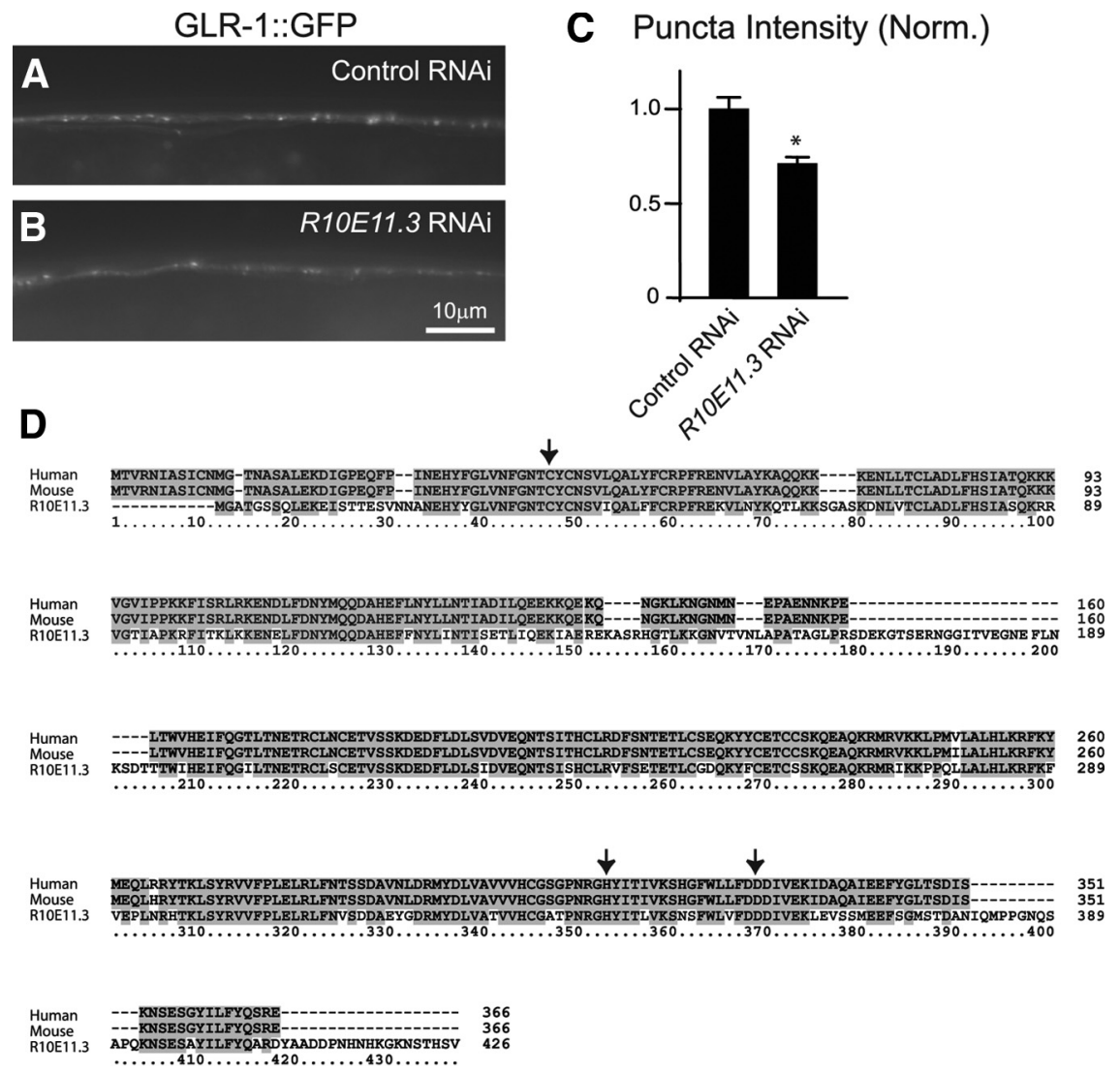

GLR-1::GFP
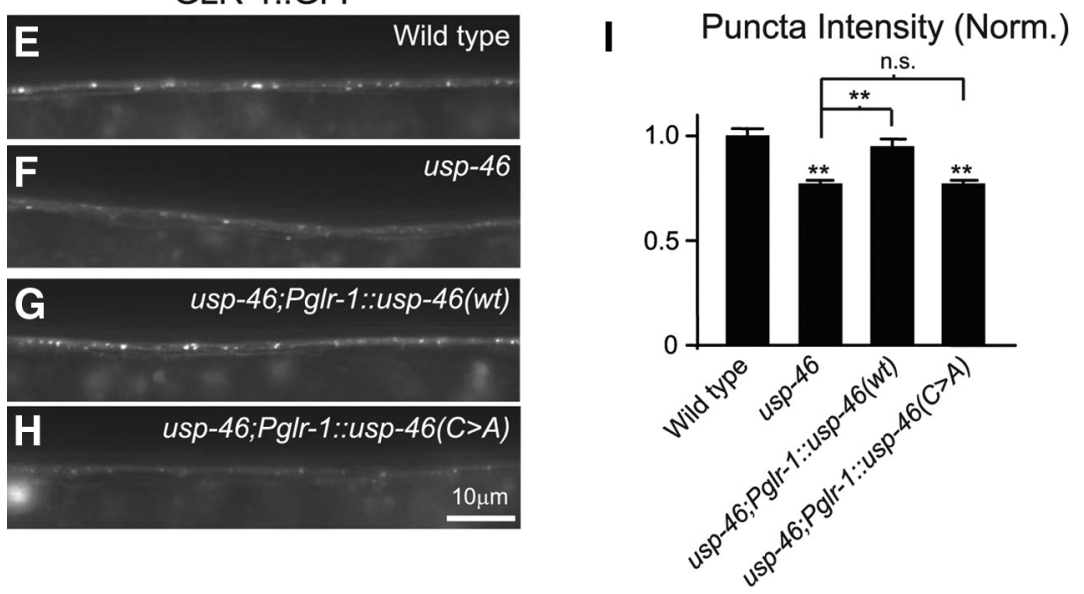

Figure 1. USP-46 regulates the abundance of GLR-1 at synapses in the VNC. $A, B$, Representative images of GLR-1::GFP puncta in the anterior ventral nerve cords of $L 4$ animals carrying an integrated GLR-1::GFP transgene (nuls25) in a strain with enhanced RNAi efficacy [lin-35(n745);eri-1(mg366)]. Animals were fed E. coli expressing a control RNAi construct (A) or an RNAi construct targeting the R10E11.3 gene $(\boldsymbol{B})$. For these and all subsequent images, animals are oriented with anterior to the left and ventral to the top. C, Quantification of GLR-1::GFP puncta intensities (normalized) for the animals fed control or R10E11.3 RNAi-expressing bacteria. Shown are the means and SEM for $n=18$ control-treated and $n=17$ R10E11.3-treated worms. Values that differ significantly from controls (Student's $t$ test) are indicated as follows: ${ }^{*} p<0.01$. D. Clustal Xalignment of the amino acid sequences of human and mouse USP-46 with the predicted C. elegans R10E11.3 gene product. Identical residues are shaded in gray. Arrows mark the essential catalytic triad residues (C, H, and D) of the USP family of cysteine proteases. $\boldsymbol{E}-\boldsymbol{G}$, Representative images of GLR-1::GFP puncta in the anterior ventral nerve cords of L4 larvae carrying an integrated GLR-1::GFP transgene (nuls24). The following genotypes are shown: wild type (E), usp-46(ok2232) $(\boldsymbol{F})$, usp-46(ok2232) rescued by expression of wild-type USP46 (wt) under the control of the glr- 7 promoter $(G)$ and usp-46(ok2232) expressing catalytically inactive USP-46(C>A) under the control of the glr- 1 promoter $(\boldsymbol{H})$. I, Quantification of GLR-1::GFP puncta intensities (normalized) for the strains pictured in $\boldsymbol{E}-\boldsymbol{H}$. Shown are the means and SEM for $n=46$ wild type, $n=42$ usp-46(ok2232), $n=29$ usp-46;Pglr-1::usp-46(wt), and $n=14$ usp-46;Pglr-1::usp-46(C $>A)$ animals. Values that differ significantly from wild type (Student's $t$ test) are denoted by * above each bar. Other comparisons are marked by brackets. All significant differences are indicated as follows: ${ }^{*} p \leq 0.01,{ }^{* *} p \leq 0.001$. n.s. denotes no significant difference between the indicated strains $(p>0.05)$. 
(Juo and Kaplan, 2004; Dreier et al., 2005; Schaefer and Rongo, 2006; Park et al., 2009). In contrast, the DUBs involved in regulating glutamate receptors have not been described for any organism.

We analyzed the abundance of GLR-1 at synapses by examining the distribution of a green fluorescent protein-tagged version of GLR-1 (GLR-1::GFP), which localizes in a punctate pattern in VNC interneurons. More than $80 \%$ of these GLR-1::GFP puncta are closely apposed to presynaptic markers, indicating that the majority of puncta correspond to postsynaptic sites (Rongo et al., 1998; Burbea et al., 2002). Expression of GLR-1::GFP under the control of its own promoter can rescue the mechanosensory defects of glr-1 null mutants, demonstrating that the tagged receptor is functional in vivo (Rongo et al., 1998).

We performed an RNAi screen to identify DUBs involved in regulating GLR-1::GFP abundance in the VNC. Knockdown of the putative DUB R10E11.3 [also known as toe-3 (Arur et al., 2009)] by RNAi resulted in decreased levels of GLR-1::GFP in the VNC compared with control RNAi-treated animals (Fig. 1A, $B$ ). We quantified this decrease by measuring the changes in GLR-1::GFP fluorescence in a $\sim 100 \mu \mathrm{m}$ region of the anterior portion of the ventral nerve cord by quantitative fluorescence microscopy. Specifically, we estimated the abundance of GLR-1::GFP at VNC puncta by measuring the peak fluorescence intensity and width of each punctum using custom-written software, as described previously (see Materials and Methods) (Burbea et al., 2002). We estimated the density of GLR-1-containing synapses by measuring the number of GLR-1::GFP puncta per unit length of the VNC. Because the GFP tag is inserted into an internal site in the cytoplasmic tail of the receptor, our measurements of GLR-1:: GFP puncta fluorescence intensities and widths in the VNC likely represent GLR-1::GFP receptors present in both the plasma membrane and subsynaptic endosomal compartments. We found that RNAi knockdown of R10E11.3 leads to a 30\% decrease $(p<0.01)$ in GLR-1::GFP puncta intensities and a 15\% decrease in puncta widths compared with control RNAi-treated animals (Fig. $1 A-C)$ [mean puncta widths $(\mu \mathrm{m}) \pm$ SEM: control, $0.87 \pm$ $0.04 ; R 10 E 11.3$ RNAi, $0.74 \pm 0.02 ; p \leq 0.01$ ]. In contrast, there was no change in the density of GLR-1::GFP puncta in R10E11.3 RNAi-treated animals compared with controls (puncta/10 $\mu \mathrm{m} \pm$ SEM: control, $1.9 \pm 0.1 ; R 10 E 11.3$ RNAi, $1.8 \pm 0.2 ; p>0.05)$. These results suggest that R10E11.3 is required to positively regulate GLR-1::GFP levels in vivo.

The protein product of the R10E11.3 gene is highly conserved and is homologous to two mammalian DUBs belonging to the USP family, USP-12 (also called UBH1) and USP-46 (Fig. $1 D$ and data not shown). USP-12 and USP-46 are small cysteine proteases of 370 and 366 aa, respectively, that share $88 \%$ sequence identity and consist primarily of the protease domain containing the essential USP catalytic triad (cysteine, histidine, and aspartic acid) (Fig. $1 D$ and data not shown) (Cohn et al., 2009). Both USP-12 and USP-46 are bona fide DUBs, because they have been shown to possess in vitro deubiquitinating activity (Hansen-Hagge et al., 1998; Quesada et al., 2004; Cohn et al., 2009; Kee et al., 2010). Mammalian USP-12 and USP-46 have been shown to interact with multiple proteins, but their biological functions are not known (Cohn et al., 2009; Sowa et al., 2009; Kee et al., 2010). The C. elegans R10E11.3 protein is $60 \%$ identical (71\% similar) to both human and murine USP-12 and USP-46. We named the C. elegans R10E11.3 gene usp-46 because, if we compare only the residues that differ between human USP-46 and USP-12, there is a higher level of identity between R10E11.3 and human USP-46 (see Materials and Methods).

To confirm the effects of R10E11.3 RNAi on GLR-1::GFP abundance in the VNC, we analyzed the distribution of GLR-1::GFP in a $u s p-46$ genetic loss-of-function mutant, usp-46(ok2232). The ok2232 allele corresponds to a $1440 \mathrm{nt}$ deletion that removes the majority of the protein product, including the critical histidine and aspartic acid residues of the catalytic triad and thus likely represents a null allele for $u s p-46$. We found that $u s p-46$ (ok2232) mutants exhibit decreased GLR-1::GFP puncta intensities $(22 \%$ decrease, $p<0.001)$ and widths (15\% decrease) in the VNC (Fig. $1 E, F, I)$ [mean puncta widths $(\mu \mathrm{m}) \pm$ SEM: wild-type, $0.94 \pm$ 0.03 ; usp-46(ok2232), $0.80 \pm 0.03 ; p<0.01$ ], with no significant changes in puncta densities (puncta/10 $\mu \mathrm{m} \pm$ SEM: wild-type, $2.2 \pm 0.1 ; u s p-46(o k 2232), 2.0 \pm 0.1 ; p>0.05)$. These results closely parallel the decreases we observed in both puncta intensities and widths in animals treated with R10E11.3 RNAi (Fig. $1 A-C$ ). Thus, a reduction in $u s p-46$ gene function by either RNAi or genetic deletion results in decreased GLR-1::GFP levels in the VNC.

\section{USP-46 acts in GLR-1-expressing interneurons to control GLR-1 abundance}

Human USP-46 is expressed in a variety of tissues, including the brain (Quesada et al., 2004). We analyzed the expression pattern of usp-46 in C. elegans using a transcriptional reporter consisting of the $u s p-46$ promoter driving expression of GFP (Pusp-46::GFP). We found that $u s p-46$ is broadly expressed in a number of tissues, including the nervous system, pharynx, body wall muscle, vulva muscle, and intestine (supplemental Fig. S1, available at www. jneurosci.org as supplemental material). usp-46 is expressed in many head and ventral cord neurons, and coexpression of a $g l r-1$ transcriptional reporter ( $P g l r-1:: d s R e d)$ with Pusp-46::GFP indicated that these include $g l r-1$-expressing neurons (supplemental Fig. S1, available at www.jneurosci.org as supplemental material). These studies suggest that $u s p-46$ may regulate GLR-1 abundance in a cell-autonomous manner.

To test specifically whether USP-46 acts in $g l r-1$-expressing interneurons to control GLR-1::GFP abundance in the VNC, we introduced a transgene expressing usp-46 cDNA under the control of the $g l r-1$ promoter [Pglr-1::usp-46(wt)] into usp-46 mutants. Expression of wild-type USP-46 exclusively in the $g l r-$ 1 -expressing cells of $u s p-46$ mutant animals restores GLR-1::GFP puncta intensities to wild-type levels (Fig. 1G,I). Puncta widths were not rescued, perhaps because of incomplete rescuing activity of the transgene [mean puncta widths $(\mu \mathrm{m}) \pm$ SEM: wildtype, $0.94 \pm 0.03$; usp-46(ok2232), $0.80 \pm 0.03$; usp-46;Pglr-1:: usp-46(wt), $0.80 \pm 0.03$; $p<0.01$ vs wild-type], but we cannot formally rule out an additional non-cell-autonomous role for usp-46. These data indicate that USP-46 functions in $g l r-1$ expressing interneurons to maintain normal GLR-1::GFP levels in the VNC.

We next wanted to determine whether the deubiquitinating activity of USP-46 is required for its effects on GLR-1::GFP abundance. Mammalian USP-46 has been shown to have a low level of deubiquitinating activity both in vitro and in a heterologous bacteria-based assay (Quesada et al., 2004; Cohn et al., 2009). Mutation of the catalytic cysteine residue in human USP-12 abolishes its ability to deubiquitinate an in vitro substrate (Cohn et al., 2009). We mutated the catalytic cysteine of C. elegans USP-46 from cysteine to alanine and expressed the catalytically-inactive USP-46(C36A) under the $g l r-1$ promoter [Pglr-1::usp-46(C>A)] in $u s p-46$ mutants. In contrast to expression of wild-type USP-46 in usp-46 mutants, which restores GLR-1::GFP to wild-type levels (Fig. 1E, F,G,I), expression of catalytically inactive USP$46(\mathrm{C}>\mathrm{A})$ in $u s p-46$ mutants does not rescue the decrease in GLR-1::GFP levels (Fig. $1 F, H, I$ ). This result suggests that the 
deubiquitinating activity of USP-46 is required in glr-1expressing interneurons to promote GLR-1 abundance.

\section{USP-46 posttranscriptionally regulates GLR-1 protein levels}

The decrease in GLR-1::GFP abundance in the VNCs of $u s p-46$ mutants could be attributable to the effects of USP-46 activity on anterograde transport from the cell body, $g l r-1$ transcription, or protein stability. If USP-46 acts early in the secretory pathway to regulate GLR-1 transport from the cell body to the VNC, then we might expect GLR-1::GFP to accumulate in the interneuron cell bodies of usp-46 mutants. For example, loss-of-function mutants in cyclin-dependent kinase-5, which regulates anterograde trafficking of GLR-1, have decreased GLR-1 in the VNC combined with a concomitant increase in GLR-1 in interneuron cell bodies (Juo et al., 2007). We measured the abundance of GLR-1::GFP in the cell bodies of PVC interneurons, which extend processes into the VNC, of wild type and $u s p-46$ mutant animals. We found that GLR-1::GFP fluorescence intensities are decreased by $22 \%$ in the cell bodies of $u s p-46$ mutants (Fig. $2 A$ ). This result suggests that USP-46 may not control anterograde transport of GLR-1.

Given that GLR-1::GFP levels decrease both in the VNC and interneuron cell bodies of $u s p-46$ mutants, we tested whether USP-46 affects transcription of $g l r-1$. If USP-46 controls GLR-1::GFP abundance by regulating glr-1 transcription, we would expect $g l r-1$ transcript levels to be decreased in usp-46 mutants. We performed real-time PCR analysis of total mRNA isolated from wild-type and $u s p-46$ mutant animals and quantified the ratio of $g l r-1$ to act-1 (actin) mRNA. We observed a 2.6-fold increase in $g l r-1 \mathrm{mRNA}$ in $u s p-46$ mutants (Fig. $2 \mathrm{~B}$ ), indicating that the decrease in GLR-1::GFP in the VNCs of these animals is not attributable to a decrease in $g l r-1$ transcription. The increase in $g l r-1$ transcription is suggestive of a potential negative feedback loop in which decreased GLR-1 at synapses in usp-46 loss-of-function animals leads to increased transcription of the receptor, but additional experiments will be necessary to test this hypothesis. This putative transcriptional compensation suggests that we may underestimate the decrease in GLR-1 protein abundance in $u s p-46$ mutants.

The reduction in GLR-1::GFP fluorescence in VNC interneurons of $u s p-46$ mutants suggests that USP-46 could act posttranscriptionally to regulate the abundance of GLR-1 protein. To test this possibility, we measured the amount of GLR-1::GFP protein in wild-type and $u s p-46$ mutants by Western blot analysis of total worm lysates. We found that $u s p-46$ mutants have decreased levels of GLR-1::GFP protein compared with wild-type animals (Fig. $2 C)$. Together, these results support a model in which USP-46 controls the levels of GLR-1 in the VNC by positively regulating the abundance of GLR-1 protein.

\section{USP-46 does not affect the distribution of synaptic markers}

To determine whether the effects of $u s p-46$ loss-of-function on GLR-1::GFP abundance are specific to GLR-1 and are not attributable to a loss of synaptic connections in $u s p-46$ mutants, we examined the distribution of the synaptic vesicle-associated protein synaptobrevin tagged with GFP (Synaptobrevin::GFP) in the VNCs of usp-46 mutant and wild-type animals. We found that the distribution of Synaptobrevin::GFP puncta was unchanged in usp-46 mutant animals compared with wild-type controls (Fig. 3) [mean puncta widths $(\mu \mathrm{m}) \pm$ SEM: wild type, $1.12 \pm 0.05$; usp46(ok2232), $0.98 \pm 0.03]$. These data indicate that glr-1expressing interneurons in $u s p-46$ mutants likely have normal presynaptic inputs and suggest that USP-46 is not generally required for synapse development in these neurons. Analysis of the
A

GLR-1::GFP in PVC Neuron Cell Bodies

B

Real Time PCR
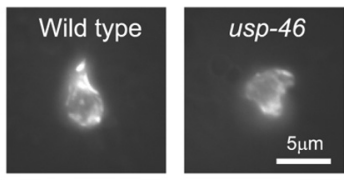

Fluorescence Intensity (Norm.)
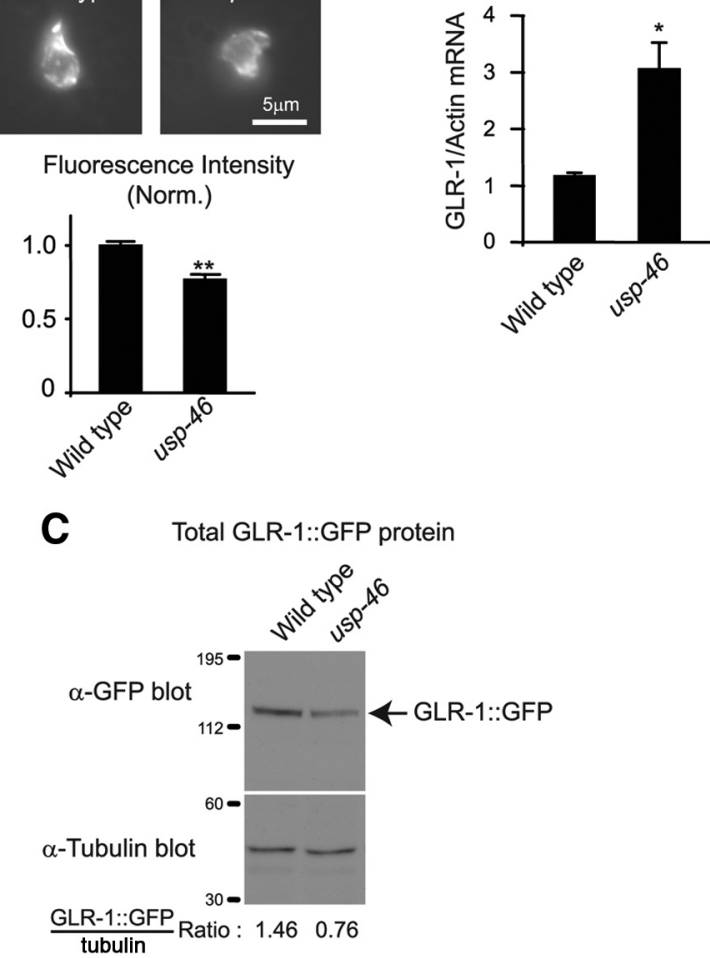

Figure 2. USP-46 regulates GLR-1 protein levels. $A, P V C$ interneuron cell bodies from wildtype ( $n=20)$ and usp-46 mutant ( $n=20$ ) L4 animals expressing GLR-1::GFP (nuls25) were imaged (top) and the mean fluorescence intensities were quantified and normalized to wildtype controls (graph). Error bars show SEM. ${ }^{* *} p \leq 0.001$, statistically significant difference from wild type (Student's $t$ test). $\boldsymbol{B}$, Results of real-time PCR analysis of mRNA levels in mixedstage populations of wild-type and usp-46 animals expressing GLR-1::GFP (nuls25). glr- 1 and actin mRNA were detected by linear range $P C R$ amplification of total CDNA from each strain using primers specific for the glr-1 and act-1 genes, respectively. Quantification of the mean ratio of glr- 1 to act- 1 mRNA measured in six total replicates of two independent mRNA preparations is shown for each genotype. Errors bars show SEM. * $p \leq 0.01$, statistically significant difference from wild type (Student's t test). C, Representative Western blot for total GLR-1::GFP, as detected with anti-GFP antibodies, of lysates from mixed-stage populations of wild-type and usp-46 mutant worms expressing GLR-1::GFP (nuls25) (top). Tubulin was also detected in these lysates by Western blot and used for normalization (bottom). Numbers listed below the blots indicate the GLR-1::GFP/tubulin integrated intensity ratios. Results from three independent experiments show that the relative amount of GLR-1 decreases by $53.4 \pm 2.6 \%$ (mean \pm SEM) in usp-46 mutants compared with controls. Molecular weight (kilodaltons) markers are indicated.

distribution of three other synaptic markers in $u s p-46$ mutants that have been shown previously to colocalize with GLR-1 in the VNC, the PDZ protein LIN-10/Mint-1 (Rongo et al., 1998), the MAGUK (membrane-associated guanylate kinase) protein MAGI-1/S-SCAM (Emtage et al., 2009), and the transmembrane CUB (complement C1r/C1s, Uegf, Bmpl) domain protein SOL-1 (Zheng et al., 2004) confirmed these results (supplemental Fig. S2, available at www.jneurosci.org as supplemental material). Together with our previous data, these findings are consistent with a relatively specific role of USP-46 in regulating GLR-1.

\section{USP-46 controls the ubiquitination of GLR-1}

Ubiquitination of GLR-1 negatively regulates its abundance in the VNC by promoting receptor endocytosis and post-endocytic degradation in the lysosome (Burbea et al., 2002; Chun et al., 2008). Therefore, one explanation for our results is that USP-46 


\section{Synaptobrevin::GFP}

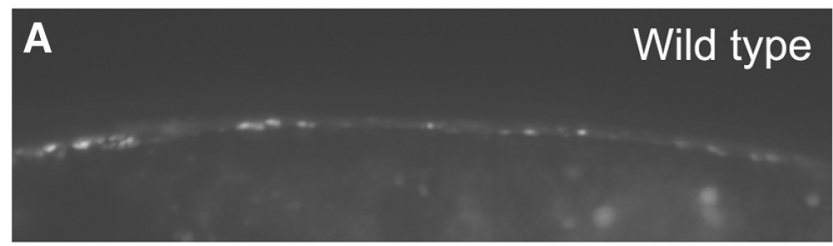

B
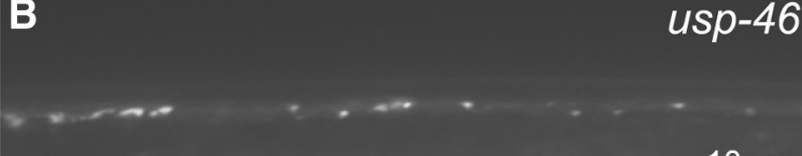

$10 \mu \mathrm{m}$

C Puncta Intensity (Norm.)

D Density (per 10 $\mu \mathrm{m}$ )
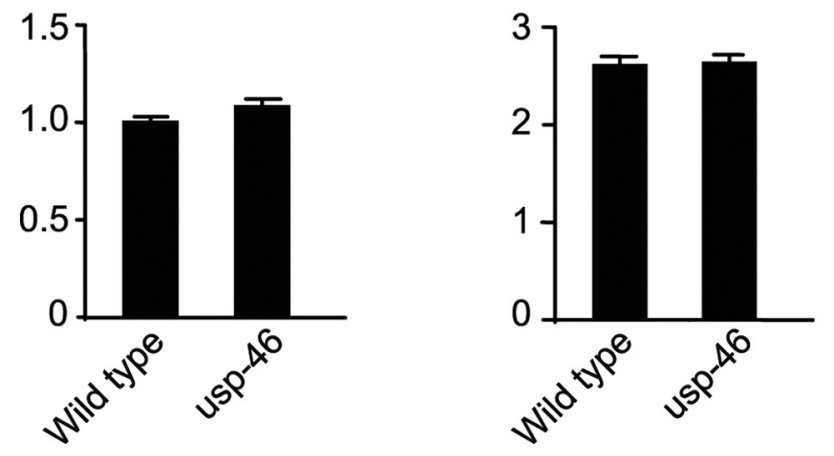

Figure 3. usp-46 mutants do not affect the distribution of Synaptobrevin. $\boldsymbol{A}, \boldsymbol{B}$, Representative images of the anterior ventral nerve cords of wild-type $(\boldsymbol{A})$ or usp-46 mutant $(\boldsymbol{B}) \mathrm{L} 4$ larvae expressing an integrated GFP-tagged synaptobrevin (Synaptobrevin::GFP) transgene under the control of the glr-1 promoter (nuls125). C, D, Quantification of Synaptobrevin::GFP puncta intensities (normalized) and densities ( $\boldsymbol{D})$ for the strains pictured in $\boldsymbol{A}$ and $\boldsymbol{B}$. Shown are the means and SEM for $n=31$ wild-type and $n=23$ usp-46(ok2232) worms.

may control the abundance of GLR-1 by directly deubiquitinating GLR-1 and preventing its degradation. We performed several experiments to test this possibility. First, we tested whether USP-46 could interact with GLR-1, as might be expected if GLR-1 were a deubiquitination target of USP-46. We incubated recombinant GST-USP-46 and catalytically inactive GST-USP46(C>A) with GLR-1::GFP isolated from worm membrane fractions. We found that both GST-USP-46 and GST-USP46(C>A) coimmunoprecipitate with GLR-1::GFP using antiGFP antibodies but not preimmune serum (Fig. 4A). Similarly, we found that GLR-1::GFP isolated from worm membrane fractions could be pulled down with GST-USP-46 and GST-USP$46(\mathrm{C}>\mathrm{A})$ but not GST alone, using glutathione Sepharose beads (Fig. $4 B$ ). In contrast, we were unable to detect an interaction between the bacterially expressed, cytoplasmic $\mathrm{C}$ terminus of GLR-1 (GLR-1C) and in vitro translated ${ }^{35}$ S-labeled USP-46 (supplemental Fig. S3, available at www.jneurosci.org as supplemental material), whereas GLR-1C could interact with a positive control, the ${ }^{35} \mathrm{~S}$-labeled PDZ protein MAGI-1 (Emtage et al., 2009). Because recombinant GST-GLR-1C is not ubiquitinated, these data are consistent with the idea that USP-46 binds to ubiquitinated GLR-1, which has been shown previously to make up $<0.5 \%$ of total GLR-1 in worms (Burbea et al., 2002). Alternatively, USP-46 interaction with GLR-1 may require other in vivo factors. Together, these data indicate that recombinant USP-46 is able to bind to GLR-1 isolated from worm membranes.
Second, we tested whether the amount of ubiquitinated GLR-1 is increased in usp-46 mutant animals, as would be expected if USP-46 deubiquitinates GLR-1. To do this, we compared the relative amounts of ubiquitinated GLR-1::GFP in wild-type and usp-46 mutant animals using a double-immunoprecipitation protocol to detect ubiquitin-GLR-1 conjugates, as described previously (Burbea et al., 2002; Juo and Kaplan, 2004; Dreier et al., 2005). Briefly, GLR-1::GFP was initially immunoprecipitated from C. elegans membrane fractions with anti-GFP antibodies (first IP), followed by a second immunoprecipitation with antiubiquitin antibodies (second IP) to enrich for ubiquitinated GLR-1 (see Materials and Methods). Ubiquitin-GLR-1::GFP conjugates immunoprecipitated by this two-step method (Fig. $4 C$, right) as well as the amount of GLR-1::GFP initially immunoprecipitated in the first IP (Fig. $4 C$, left) were subsequently detected by Western blotting with anti-GFP antibodies. We found that $u s p-46$ mutant animals have an increased proportion of ubiquitinated GLR-1::GFP (normalized to GLR-1::GFP in the first IP) compared with wild-type controls (Fig. 4C). The decreased amount of GLR-1::GFP in the first IP from $u s p-46 \mathrm{mu}-$ tants (Fig. 4C, left) compared with control is consistent with the decrease of total GLR-1::GFP protein observed in $u s p-46$ mutant animals by total Western blot analysis (Fig. 2). Saturation of the anti-ubiquitin second IP with purified ubiquitin abolished the detection of ubiquitin-GLR-1 conjugates, confirming that the bands we observed by Western blot are indeed ubiquitinated GLR-1:: GFP (supplemental Fig. S4A, available at www.jneurosci.org as supplemental material). Additional controls using anti-ubiquitin antibodies instead of anti-GFP antibodies for Western blot detection of the ubiquitin-GLR-1::GFP conjugates from the second IP further confirmed the identity of the slower migrating ubiquitinGLR-1 bands (supplemental Fig. S4B, available at www. jneurosci.org as supplemental material). We next attempted to test whether recombinant USP-46 could deubiquitinate GLR-1. Only a small amount of our bacterially expressed GST-USP-46 was active as determined using $\mathrm{HA}-\mathrm{Ub}-\mathrm{VME}$, which can be used to covalently label the active-site cysteine of active DUBs (supplemental Fig. S5A, available at www.jneurosci.org as supplemental material) (Ovaa et al., 2004). This is consistent with studies showing that recombinant mammalian USP-46 and USP-12 exhibit very low levels of in vitro DUB activity (Cohn et al., 2009; Kee et al., 2010). Although mammalian USP-46 and USP-12 DUB activity can be stimulated by two proteins UAF-1 and WDR20 (Cohn et al., 2009; Kee et al., 2010), the C. elegans homologs of these genes have not yet been identified. Nevertheless, incubation of GST-USP-46 with GLR-1::GFP isolated from worm membrane fractions resulted in a small decrease (15-20\%) in the relative amount of ubiquitin-GLR-1 conjugates compared with GLR-1::GFP incubated with catalytically inactive GST-USP46(C>A) (supplemental Fig. S5 B, C, available at www.jneurosci. org as supplemental material). This low level of DUB activity is consistent with the low activity of our bacterially expressed GSTUSP-46 and suggests that, like mammalian USP-12 and USP-46, C. elegans USP-46 may also require other factors for full activity. Together, these data indicate that USP-46 negatively regulates the amount of ubiquitinated GLR-1 in vivo.

Finally, we tested whether the decrease in GLR-1::GFP abundance seen in $u s p-46$ mutants could be prevented by blocking ubiquitination of GLR-1. Because ubiquitin is covalently attached to lysine residues on target proteins, mutation of all four lysine residues in the cytoplasmic tail of GLR-1 to arginine [GLR-1(4KR)::GFP] results in a receptor that cannot be ubiquitinated and thus accumulates at synapses in the VNC (Burbea et al., 2002). We analyzed the 
distribution of this non-ubiquitinatable GLR-1(4KR)::GFP in wild-type and usp-46 mutant animals. In contrast to wild-type GLR-1::GFP, which decreases in abundance in the VNCs of usp-46 mutants (Fig. $1 E, F, I)$, the abundance of GLR-1(4KR):: GFP is unaltered in $u s p-46$ mutants compared with wild-type animals (Fig. $4 D-F$ ) (mean puncta widths $(\mu \mathrm{m}) \pm$ SEM: wild type, $1.04 \pm 0.03$; usp-46(ok2232), $1.05 \pm$ $0.04 ; p>0.05)$. Similar to wild-type GLR-1::GFP, the density of GLR-1(4KR):: GFP does not change in usp-46 mutant animals compared with controls (puncta/10 $\mu \mathrm{m} \pm$ SEM: wild type, $2.3 \pm 0.08$; usp46(ok2232), $2.4 \pm 0.1 ; p>0.05$ ). This result suggests that ubiquitination of GLR-1::GFP is required for the decrease in GLR-1::GFP abundance observed in $u s p-46$ mutant animals. These data demonstrate that USP-46 promotes the deubiquitination of GLR-1, which in turn increases the abundance of GLR-1 in the VNC.

\section{USP-46 functions in the same pathway as clathrin-mediated endocytosis to regulate GLR-1}

The abundance of AMPA receptors in the postsynaptic membrane is likely derived from a recycling pool of receptors undergoing exocytosis, endocytosis, and postendocytic degradation (Ehlers, 2000; Lin et al., 2000; Shepherd and Huganir, 2007). Previous studies have shown that ubiquitination of GLR-1 provides a signal for the clathrin-mediated endocytosis and subsequent targeting of the receptor for degradation (Burbea et al., 2002; Chun et al., 2008). Because USP-46 regulates both GLR-1 ubiquitination and degradation, we tested whether USP-46 acts in the same pathway as clathrin-mediated endocytosis. If the decrease in GLR-1::GFP abundance seen in $u s p-46$ mutants is attributable to increased clathrin-mediated endocytosis of ubiquitinated receptors and their subsequent degradation, then preventing endocytosis should abrogate this effect. To test this possibility, we blocked endocytosis with mutations in unc-11 AP180, a clathrin adaptin required for endocytosis of GLR-1 (Nonet et al., 1999; Burbea et al., 2002). GLR-1::GFP accumulates in the VNCs of unc-11 AP180 mutants (Burbea et al., 2002). In contrast to our prediction, we found that unc-11 AP180;usp-46 double mutants exhibit GLR-1::GFP puncta intensities and widths that are similar, although not identical, in value to those seen in usp-46 single mutants (Fig. 5) (supplemental Fig. S6, available at www.jneurosci.org as supplemental material). Thus, usp-46 loss-of-function mostly prevents the accumulation of GLR-1::GFP caused by unc-11 AP180 mutation. This result is inconsistent with the simplest model that USP-46
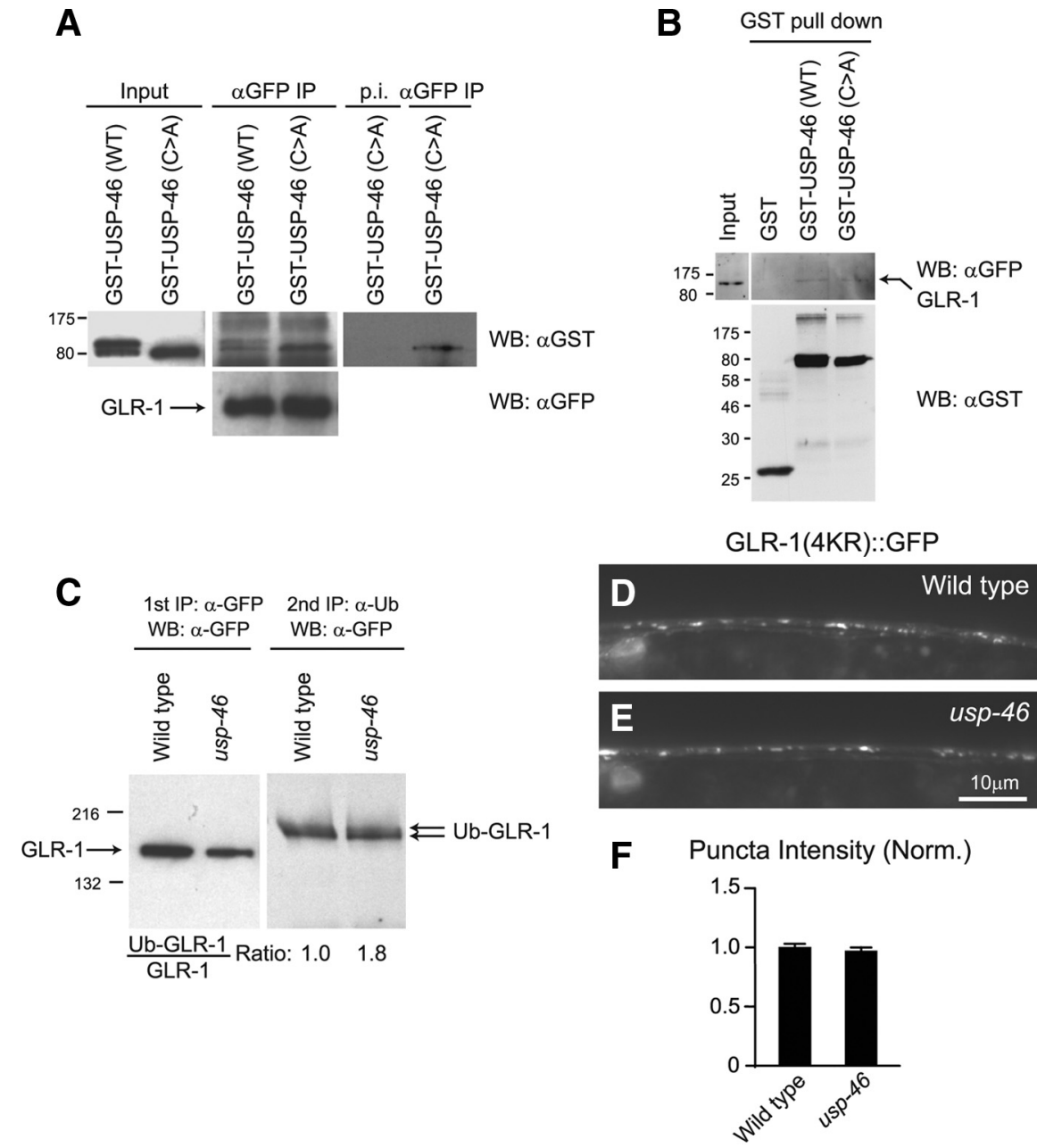

Figure 4. USP-46 regulates GLR-1 ubiquitination. $A$, Representative immunoprecipitation experiments showing the amount of recombinant GST-USP-46 or GST-USP-46(C $>A$ ) that coimmunoprecipitates with GLR-1::GFP from membranes prepared from mixed-stage populations of wild-type animals expressing GLR-1::GFP. The top three panels show Western blots (WB) probed with monoclonal anti-GST antibodies, and the bottom panel shows a Western blot probed with monoclonal anti-GFP antibodies. Input lanes (left) represent $1 \%$ of recombinant proteins that were incubated with GLR-1::GFP. p.i., Preimmune serum. Higher salt (250 $\mathrm{mm}$ ) washes were used in the immunoprecipitations in the right panel to reduce background. $\boldsymbol{B}$, Representative GST pull-down experiments showing that recombinant GST-USP-46 and GST-USP-46(C>A) can associate with GLR-1::GFP from worm membrane fractions. The top panels show Western blots probed with monoclonal anti-GFP antibodies, and the bottom panel shows a Western blot probed with monoclonal anti-GST antibodies. Input represents $1 \%$ of the GLR-1::GFP membranes that were incubated with the various GST-tagged proteins. C, Representative immunoprecipitation experiments detecting the relative amounts of ubiquitinated GLR-1::GFP in membranes prepared from mixed-stage populations of wild-type and usp-46 mutant animals expressing the GLR-1::GFP transgene (nuls25). Total GLR-1::GFP was first immunoprecipitated using polyclonal anti-GFP antibodies (first IP). This was followed by a second, sequential immunoprecipitation of ubiquitin-GLR-1 conjugates using polyclonal anti-ubiquitin antibodies (second IP). Western blot analyses were used to detect immunoprecipitated proteins from each IP. Immunoprecipitated GLR-1::GFP from the first IP and Ubiquitin-GLR-1::GFP conjugates immunoprecipitated in the second IP were detected with monoclonal anti-GFP antibodies. One hundred twenty times more material was loaded for the anti-GFP blot of the second IP than for the anti-GFP blot of the first IP. Numbers listed below the right panel indicate the ratios of the amount of ubiquitinated GLR-1 (right) to the amount of total immunoprecipitated GLR-1::GFP (left) (Ub-GLR-1-GLR-1). Results from three independent experiments show that the relative amount of Ub-GLR-1 increases by $71.8+4.7 \%$ (mean \pm SEM) in usp-46 mutants compared with controls. Molecular weight (kilodaltons) markers are indicated. $\boldsymbol{D}, \boldsymbol{E}$, Representative images of the anterior ventral nerve cords of wild-type $(\boldsymbol{D})$ or usp-46 mutant $(\boldsymbol{E})$ L4 larvae expressing the integrated GLR-1(4KR)::GFP transgene (nuls108). $\boldsymbol{F}$, Quantification of GLR-1(4KR)::GFP puncta intensities (normalized) for the strains pictured in $\boldsymbol{D}$ and $\boldsymbol{E}$. Shown are the means and SEM for $n=28$ wild-type and $n=27$ usp-46(ok2232) mutant worms.

functions exclusively on post-endocytic GLR-1 delivered to an internal compartment via an UNC-11 AP180/clathrin pathway. Instead, this result suggests that USP-46 may function, in part, by preventing the degradation of newly synthesized GLR-1 receptors delivered to an internal compartment en route to the plasma membrane. 

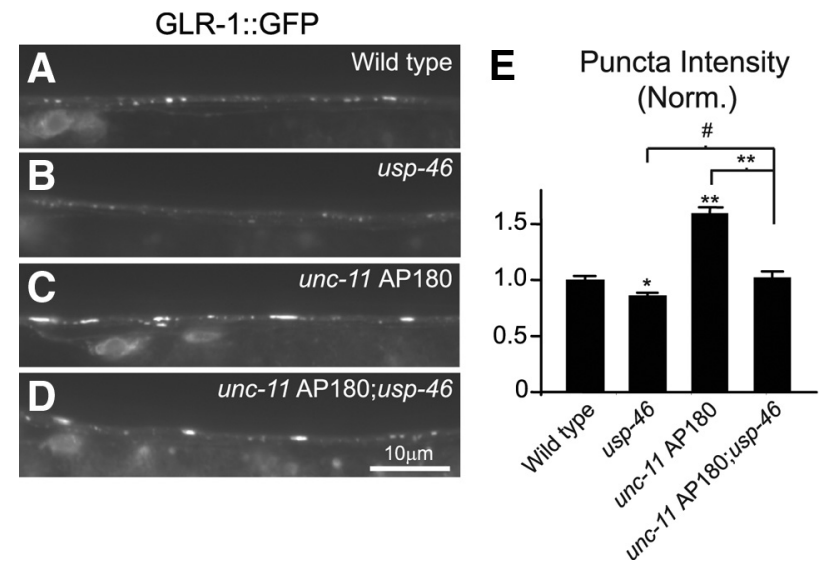

Figure 5. The role of USP-46 in the clathrin-mediated endocytosis pathway. $\boldsymbol{A}-\boldsymbol{D}$, Representative images of GLR-1::GFP puncta in the anterior ventral nerve cords of $L 4$ larvae expressing GLR-1::GFP (nuls25). The following genotypes are shown: wild type (A), usp-46(ok2232) (B), unc-11(e47) AP180 (C), unc-11 AP180;usp-46 (D). E, Quantification of GLR-1::GFP puncta intensities (normalized) for the strains pictured in $\boldsymbol{A}-\boldsymbol{D}$. Shown are the means and SEM for $n=$ 59 wild-type, $n=41$ usp-46 (ok2232), $n=20$ unc- 11 AP180(e47), and $n=24$ unc-11 AP180; usp-46 animals. Values that differ significantly from wild type (Student's $t$ test) are denoted by ${ }^{*}$ above each bar. All significant differences are indicated as follows: ${ }^{*} p \leq 0.05,{ }^{*} p \leq 0.01$, $*^{* *} p \leq 0.001$.

If USP-46 functions in the VNC to regulate GLR-1, then we might expect USP-46 to be localized to the VNC. We analyzed the subcellular localization of USP-46 in VNC interneurons by examining the distribution of an mCherry-tagged version of USP-46 (mCherry::USP-46) expressed under the control of the $g l r-1$ promoter. We found that mCherry::USP-46 is localized to discrete puncta in the cell body and is present in the VNC in which it is localized both diffusely throughout the cytoplasm and to punctuate structures (supplemental Fig. S7, available at www. jneurosci.org as supplemental material). These mCherry:: USP-46 puncta do not overlap extensively with GLR-1::GFP in the VNC (supplemental Fig. S7, available at www.jneurosci.org as supplemental material), consistent with other potential roles for USP-46 in neurons and the transient nature of enzyme-substrate interactions. Nevertheless, these results are consistent with the idea that USP-46 is present in the cell body and the VNC in which it could function to regulate GLR-1 abundance.

DUBs have been shown previously to play a role in controlling the abundance of newly synthesized proteins in the ER. Polyubiquitination of misfolded proteins by ubiquitin ligases in the ER leads to their retrotranslocation and degradation in the proteasome as part of a quality control mechanism called ER-associated degradation (ERAD) (Raasi and Wolf, 2007). Because ERAD is regulated by the activity of DUBs (Raasi and Wolf, 2007), we tested whether USP-46 regulates GLR-1 in the ER. We first examined whether mCherry::USP-46 localization to puncta in the cell body colocalizes with the ER marker KDEL-venus (Chun et al., 2008). We found that mCherry::USP-46 localization does not overlap with KDEL-venus in the cell body (supplemental Fig. S8, available at www.jneurosci.org as supplemental material). Second, we used an Endo H assay to measure the amount of GLR-1 in the ER. GluRs are glycosylated in the ER with simple mannoserich carbohydrates that are sensitive to digestion with Endo $\mathrm{H}$. GluRs mature in the Golgi and receive complex carbohydrate modifications that are resistant to digestion with Endo H. Quantitation of the ratio of Endo $\mathrm{H}$-sensitive to Endo $\mathrm{H}$-resistant GluRs measures the amount of GluRs retained in the ER. This assay has been used to study the amount of mammalian and $C$.

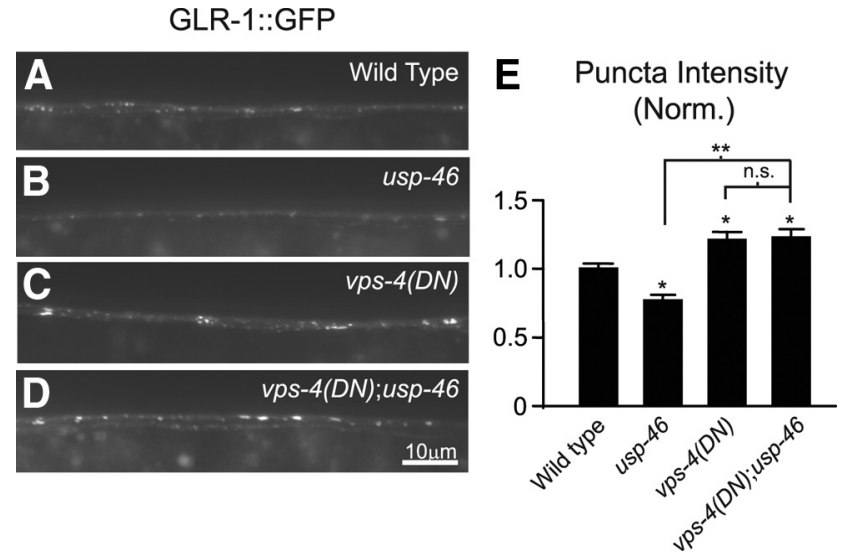

Figure 6. USP-46 acts upstream of the MVB/lysosome pathway. $\boldsymbol{A}-\boldsymbol{D}$, Representative images of GLR-1::GFP puncta in the anterior ventral nerve cords of $L 4$ larvae expressing GLR-1::GFP (nuls24). The following genotypes are shown: wild type (A), usp-46(ok2232) (B), animals expressing vps-4(DN) (C), and usp-46(ok2232) mutant animals expressing vps-4(DN) (D). E, Quantification of GLR-1::GFP puncta intensities (normalized) for the strains pictured in $\boldsymbol{A}-\boldsymbol{D}$. Shown are the means and SEM for $n=26$ wild type, $n=19$ usp-46(ok2232), $n=22$ vps-4(DN), and $n=26$ vps-4(DN);usp-46 animals. Values that differ significantly from wild type (Student's $t$ test) are denoted by * above each bar. All significant differences are indicated as follows: ${ }^{*} p \leq 0.01,{ }^{* *} p \leq 0.001$. n.s. denotes no significant difference between the indicated strains $(p>0.05)$.

elegans GluRs in the ER (Tomita et al., 2001; Grunwald and Kaplan, 2003; Mu et al., 2003). We found that the relative levels of Endo H-sensitive GLR-1 in usp-46 mutants were unaltered compared with wild-type animals (supplemental Fig. S8, available at www.jneurosci.org as supplemental material). These results suggest that USP-46 does not regulate the amount of GLR-1 in the endoplasmic reticulum.

\section{USP-46 regulates GLR-1 degradation in the MVB/lysosome pathway}

We next tested whether USP-46 regulates the degradation of GLR-1 in the MVB/lysosome pathway. Studies in yeast and mammalian systems have shown that ubiquitin provides a signal for endocytosis and subsequent sorting of membrane proteins into MVBs for ultimate degradation in the lysosome (Katzmann et al., 2001, 2002; Urbanowski and Piper, 2001; Bilodeau et al., 2003). Deubiquitination of receptors in the endosome can prevent targeting to the MVB and promote recycling of receptors back to the plasma membrane (Katzmann et al., 2002; Hicke and Dunn, 2003). The AAA ATPase VPS-4 is required for the disassembly of MVB protein sorting complexes and is essential for the internalization of cargo from the endosomal limiting membrane into the internal vesicles of the MVB (Babst et al., 2002; Katzmann et al., 2002). Recent work has shown that post-endocytic degradation of ubiquitinated GLR-1 occurs via VPS-4-mediated sorting into the MVB/lysosome pathway (Chun et al., 2008). VPS-4 can act in the VNC because GLR-1::GFP accumulates in the VNC of animals expressing a dominant-negative version of VPS-4 [vps4(DN)] (Chun et al., 2008). To determine whether USP-46 functions in the MVB/lysosome pathway to control GLR-1 abundance, we tested whether blocking GLR-1 degradation via the $\mathrm{MVB} /$ lysosome by expression of $v p s-4(D N)$ could prevent the decrease in GLR-1::GFP observed in usp-46 mutants. We found that expression of $v p s-4(D N)$ completely blocked the reduction in GLR-1::GFP puncta intensities and widths caused by $u s p-46$ mutation (Fig. 6) (supplemental Fig. S6, available at www. jneurosci.org as supplemental material), suggesting that USP-46 
GLR-1::GFP (Total)

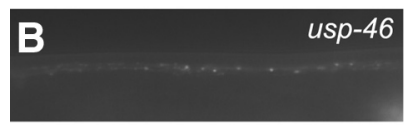

C

GFP Puncta Intensity (Norm.)

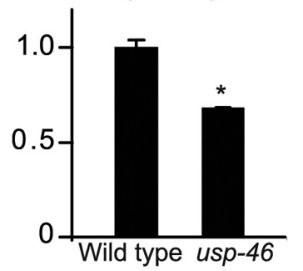

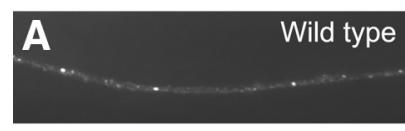

a-HA-Alexa 594

aHA-Alexa Puncta Intensity (Norm.)

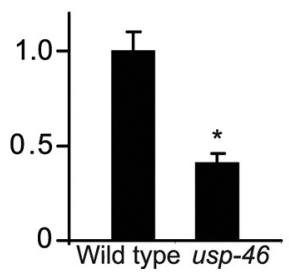

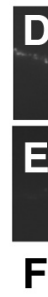

Figure 7. usp-46 mutants have decreased surface levels of GLR-1. $A, B$, Representative images of GLR-1::GFP puncta in the anterior ventral nerve cords of wild-type $(A)$ and usp46(ok2232) (B) young adult animals expressing HA::GLR-1::GFP ( pzls12). D, $\boldsymbol{E}$, Representative images of anti-HA Alexa Fluor 594-immunostained HA::GLR-1::GFP puncta in the anterior ventral nerve cords of wild-type (D) and usp-46(ok2232) (E) young adult animals expressing HA::GLR-1::GFP ( pzls12). C, $\boldsymbol{F}$, Quantification of GLR-1::GFP puncta intensities (normalized) ( $\boldsymbol{C}$ ) or anti-HA-Alexa Fluor 594 puncta intensities (normalized) $(\boldsymbol{F})$ for the strains pictured in $A, B$ and $\boldsymbol{D}, \boldsymbol{E}$. Shown are the normalized means and SEM for $n=17$ wild-type and $n=18$ usp46(ok2232) animals. Values that differ significantly from wild type (Student's $t$ test) are denoted by ${ }^{*}$ above each bar. All significant differences are indicated as ${ }^{*} p \leq 0.01$.

acts upstream of the MVB/lysosome pathway (i.e., in a pre-MVB compartment such as the endosome), to control GLR-1::GFP abundance. Consistent with this idea, mCherry::USP-46 partially colocalizes with the endosome marker Venus::RAB-5 in both the cell body and the VNC (supplemental Fig. S $F-N$, available at www.jneurosci.org as supplemental material). In addition, we found that the relative amount of ubiquitin-GLR-1 conjugates increased in $u s p-46$ mutant animals expressing $v p s-4(D N)$ (supplemental Fig. S8O, available at www.jneurosci.org as supplemental material), as would be expected if USP-46 regulates GLR-1 deubiquitination upstream of the MVB/lysosome pathway. Together, our data suggest a model in which USP-46 functions in the cell body and VNC at a pre-MVB compartment (i.e., an endosome) to deubiquitinate GLR-1 and prevent its degradation in the MVB/lysosome.

usp-46 mutants have reduced surface GLR-1 levels and exhibit defects in glutamate-dependent behaviors

Because USP-46 regulates the abundance of GLR-1 at synapses in the VNC, we tested whether the amount of surface GLR-1 in the VNC was altered in usp-46 mutant animals. We generated transgenic animals expressing HA::GLR-1::GFP under the control of the $g l r-1$ promoter in which GLR-1 is tagged with both an extracellular HA-epitope tag and an intracellular GFP tag (Zheng et al., 2004; Wang et al., 2008a). Surface GLR-1 can be labeled by injecting fluorescently tagged anti-HA antibodies into the pseudocoelum of living animals, as described previously (Zheng et al., 2004; Wang et al., 2008a) (see Materials and Methods). Consistent with our results in Figure 1, we found that the total abundance of HA::GLR-1::GFP (GFP fluorescence) in the VNC decreased by $32 \%$ in $u s p-46$ mutants compared with control animals (Fig. $7 A-C$ ). We found that the amount of surface HA::GLR-1::GFP (Alexa 594 fluorescence) decreased by $59 \%$ in usp-46 mutant animals compared with wild-type controls (Fig.
A

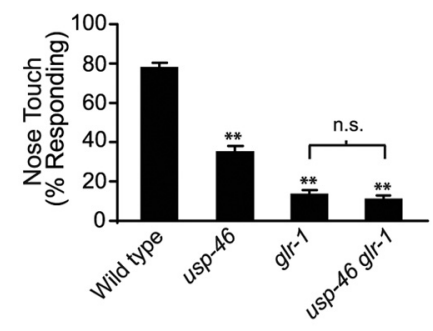

B

C
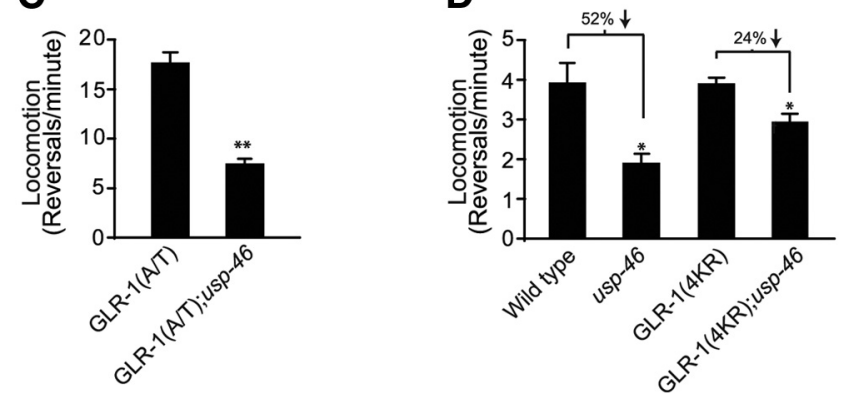

Figure 8. usp-46 mutants have defects in GLR-1-dependent behaviors. $\boldsymbol{A}$, Graphs showing the average percentage of worms responding to nose touch for the following genotypes: $n=$ 28 wild type, $n=25$ usp-46(ok2232), $n=28 \mathrm{glr}-1$ (n2461), and $n=10$ usp-46(ok2232) glr1(n2461). $\boldsymbol{B}$, Graphs showing the average number of reversals per minute for spontaneous locomotion assays performed on worms of the following genotypes: $n=28$ wild type, $n=26$ usp-46(ok2232), $n=22 \mathrm{glr}-1$ (n2461), and $n=8$ usp-46(ok2232)glr-1(n2461). C, Graphs showing the average number of reversals per minute for spontaneous locomotion assays performed on worms of the following genotypes: $n=12$ wild-type animals expressing $G L R-1(A / T)$ (nuls80) and $n=12$ usp-46(ok2232) mutant animals expressing GLR-1(A/T). D, Graphs showing the average number of reversals per minute for spontaneous locomotion assays performed on worms of the following genotypes: $n=8$ wild type, $n=8$ usp-46(ok2232), $n=8$ wild-type animals expressing GLR-1(4KR)::GFP(nuls108), and $n=8$ usp-46(ok2232) mutant animals expressing GLR-1(4KR)::GFP. Error bars show SEM. * denote significant differences from wild type $\left({ }^{*} p \leq 0.01,{ }^{* *} p \leq 0.001\right)$. n.s. denotes no significant difference between the indicated strains $(p>0.05)$.

$7 D-F$ ). The ratio of surface to total GLR-1 (Alexa Fluor 594 puncta fluorescence/GFP puncta fluorescence) also decreased by $40 \%$ in $u s p-46$ mutants compared with wild-type animals. Together with our previous data, these results suggest that USP-46 prevents the degradation of GLR-1 and promotes its surface expression in the VNC.

The decrease in surface levels of GLR-1 in the VNC of usp-46 mutants should result in reduced signaling of GLR-1-containing synapses and, consequently, defects in GLR-1-dependent behaviors. Two behavioral assays can be used to assess the function of GLR-1-containing synapses: the nose touch assay and a spontaneous locomotion assay (Kaplan and Horvitz, 1993; Hart et al., 1995; Maricq et al., 1995; Zheng et al., 1999). Gentle touch to the nose of the worm results in a mechanosensory reflex that induces backward locomotion, which requires signaling through GLR-1 receptors. Mutants with defects in glutamatergic signaling, such as $g l r-1$ and eat-4 VGLUT (a presynaptic vesicular glutamate transporter) null mutants, show severe defects in their responses to nose touch (Fig. 8A) (Hart et al., 1995; Maricq et al., 1995; Berger et al., 1998). Consistent with lower levels of GLR-1 at VNC synapses, we found that usp-46 mutants exhibit a 55\% reduction in nose touch responsiveness compared with wild-type animals, indicative of decreased GLR-1 signaling (Fig. $8 \mathrm{~A}$ ). If the effects of usp-46 mutation on nose touch responses are mediated by its effects on GLR-1 abundance, then a double mutant of $u s p-46$ and glr-1 should have a non-additive phenotype. We found that 
usp-46 glr-1 double-mutant animals had decreased nose touch responses that were indistinguishable from $g l r-1$ single-mutant animals $(p=0.5)$ (Fig. $8 A$ ). These results suggest that USP-46 and GLR-1 function in the same pathway to regulate nose touch responsiveness.

We next tested whether usp-46 mutant animals have altered locomotion behavior. Spontaneous locomotion in C. elegans is characterized by periods of forward movement interrupted by brief periods of backward movement. The amount of glutamatergic signaling by VNC interneurons governs the frequency of these spontaneous reversals. For example, mutants with decreased glutamatergic signaling, such as eat-4 and glr-1 null mutants, have decreased reversal frequencies compared with wild-type animals (Fig. 8B) (Zheng et al., 1999; Brockie et al., 2001b; Burbea et al., 2002). In contrast, mutants with increased glutamatergic signaling reverse more frequently than wild-type animals (Zheng et al., 1999; Burbea et al., 2002; Juo and Kaplan, 2004; Schaefer and Rongo, 2006; Juo et al., 2007). We found that spontaneous reversal frequencies in $u s p-46$ mutants are reduced by $\sim 40 \%$ compared with wild-type animals (Fig. $8 \mathrm{~B}$ ). We also used the locomotion assay to test whether USP-46 and GLR-1 function in the same pathway and found that $u s p-46 \mathrm{glr}$ - 1 doublemutant animals have decreased reversal frequencies that were indistinguishable from $g l r-1$ single-mutant animals $(p=0.3)$ (Fig. $8 \mathrm{~B}$ ). This result is consistent with our nose touch data and suggests that USP-46 and GLR-1 function in the same pathway to regulate GLR-1-dependent behaviors. To further test whether USP-46 regulation of reversal frequencies is mediated by GLR-1, we examined whether $u s p-46$ mutation could suppress the effects of a dominant-active version of GLR-1 [GLR-1(A/T)] on locomotion behavior. Substitution of a conserved alanine near the pore domain to a threonine residue in mouse GluRdelta2(A/T) or C. elegans GLR-1(A/T) results in a gain-of-function, constitutively active receptor (Zheng et al., 1999; Kohda et al., 2000). Animals expressing GLR-1(A/T) under the control of the $g l r-1$ promoter have increased reversal frequencies consistent with increased glutamatergic signaling (Zheng et al., 1999, 2004). We found that $u s p-46$ mutation strongly suppresses the increased reversal frequencies caused by expression of GLR-1(A/T) (Fig. $8 C)$. Because our data suggest that USP-46 regulates the abundance of GLR-1 by deubiquitinating the receptor and preventing its degradation in the lysosome, we tested whether expression of non-ubiquitinatable GLR-1(4KR)::GFP, which is resistant to the effects of $u s p-46$ mutation (Fig. $4 D-F$ ), could suppress the effects of usp-46 mutation on locomotion behavior. We found that GLR-1(4KR)::GFP partially blocks the ability of $u s p-46$ mutation to decrease reversal frequencies (Fig. $8 D$ ). Together, these results suggest that usp-46 mutants have defects in GLR-1-dependent behaviors and that USP-46 controls these behaviors by regulating postsynaptic surface levels of GLR-1.

\section{Discussion}

Ubiquitin has emerged as an important regulator of synapse development and plasticity, and the relevant E3 ubiquitin ligases are beginning to be defined (Bingol and Schuman, 2005; Yi and Ehlers, 2007). It is also becoming apparent that the balance between ubiquitination and deubiquitination is critical for a variety of cellular functions (Song and Rape, 2008); however, there is much to be learned about the DUBs that function in the nervous system. Here we identify USP-46 as the first DUB to control GluR trafficking and show that it positively regulates the abundance of GLR-1 in the VNC of C. elegans. We show that $u s p-46$ mutants have decreased levels of surface and total GLR-1::GFP in the VNC
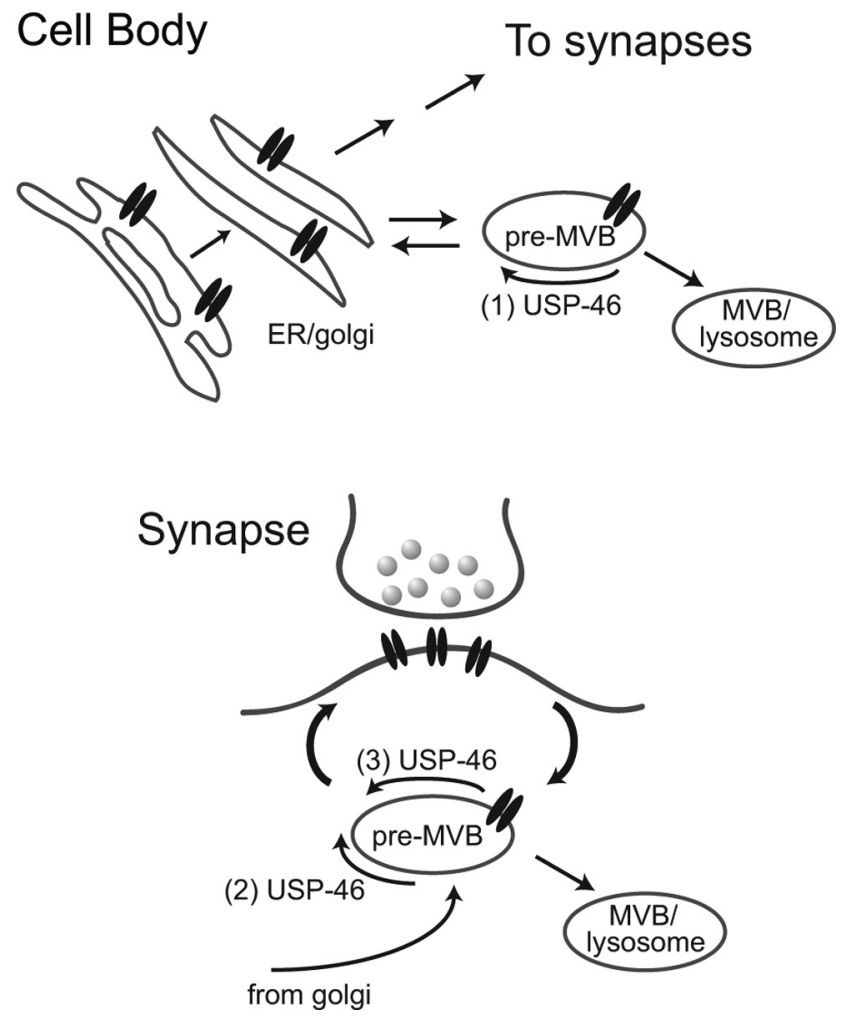

Figure 9. Model for USP-46 regulation of GLR-1. USP-46 functions in both the cell body and the ventral nerve cord at a pre-MVB compartment (i.e., endosome) to deubiquitinate GLR-1 and prevent its degradation in the MVB/lysosome. USP-46 prevents the degradation of newly synthesized GLR-1 in the cell body (1) and the VNC (2) and promotes its surface expression. We propose that USP-46 may also prevent the degradation of internalized GLR-1 at the synapse and promote its recycling back to the plasma membrane (3). The overall function of USP-46 is to control the amount of GLR-1 in the donor compartment (i.e., endosome) available for delivery to the postsynaptic membrane.

and display corresponding defects in $g l r-1$-mediated behaviors. Loss of $u s p-46$ results in increased levels of ubiquitinated GLR-1 and promotes degradation of GLR-1 via the MVB/lysosome pathway. These data suggest a model whereby USP-46 promotes the abundance of GLR-1 at synapses by acting in a pre-MVB compartment (i.e., endosome) to deubiquitinate GLR-1 and thus prevent its lysosomal degradation (Fig. 9).

\section{Identification of USP-46}

We identified the DUB R10E11.3 in an RNAi screen for regulators of GLR-1 trafficking and named it USP-46 based on its homology to the mammalian USP-46 (Fig. 1A--D). The R10E11.3/ usp-46 gene is implicated in diverse cellular processes based on several large RNAi screens (Sieburth et al., 2005; Ceron et al., 2007; Kahn et al., 2008; Arur et al., 2009) and a recent genetic study linking USP-46 to depression-like behaviors (Tomida et al., 2009). However, the specific roles of USP-46 in these various processes were not defined. Our finding that USP-46 regulates GLR-1 ubiquitination and abundance identifies the first specific function and target for this DUB.

\section{USP-46 regulates GLR-1 deubiquitination and degradation}

Several lines of evidence indicate that USP-46 negatively regulates GLR-1 degradation by deubiquitinating the receptor. First, the abundance of GLR-1::GFP decreases in the VNCs of usp-46 loss-of-function mutants and in animals treated with $u s p-46$ RNAi (Fig. 1). This effect can be rescued by expression of wild- 
type USP-46 but not catalytically inactive USP-46(C $>$ A) in VNC interneurons. Second, GLR-1::GFP also decreases in the cell bodies of VNC interneurons in usp-46 mutants (Fig. 2A). Third, biochemical assays indicate that total GLR-1::GFP protein levels are reduced in $u s p-46$ mutants (Fig. $2 C$ ), that the amount of ubiquitinated GLR-1 increases in usp-46 mutants (Fig. 4C), and that recombinant USP-46 interacts with GLR-1 isolated from worm membranes (Fig. $4 A, B$ ). Fourth, a version of GLR-1 [GLR-1(4KR)::GFP] that cannot be ubiquitinated and degraded (Burbea et al., 2002) is resistant to the effects of $u s p-46$ mutation (Fig. $4 D-F)$. Fifth, expression of $v p s-4(D N)$, which inhibits the degradation of GLR-1 in the MVB/lysosome pathway (Chun et al., 2008), completely blocks the decrease in GLR-1::GFP observed in usp-46 mutants (Fig. 6). Sixth, usp-46 mutants have decreased levels of surface GLR-1 in the VNC (Fig. 7). This effect of USP-46 on surface GLR-1 is greater than its effect on total GLR-1, suggesting that USP-46 promotes the surface expression of the receptor. Finally, usp-46 mutant animals have defects in GLR-1-dependent behaviors that are consistent with decreased glutamatergic transmission, and non-ubiquitinatable GLR$1(4 \mathrm{KR})$ partially suppresses the effects of usp-46 on locomotion (Fig. 8). This partial suppression could be explained by other roles for USP-46 at the synapse, such as regulation of other proteins required for GLR-1 function. Together, these results suggest that USP-46 regulates the abundance of GLR-1 at synapses by deubiquitinating the receptor and preventing its degradation in the lysosome.

DUBs have been shown to regulate the abundance of newly synthesized proteins in the ER via the ERAD quality control mechanism (Raasi and Wolf, 2007). Indeed, recent reports identified an ubiquitin ligase and a DUB that control the degradation of misfolded neurotransmitter receptors in the ER (Kato et al., 2005; Milojevic et al., 2006). It is unlikely that USP-46 functions at the ER to regulate GLR-1 levels. mCherry::USP-46 does not colocalize with the ER marker KDEL::venus, and usp-46 mutants have wild-type levels of GLR-1 in the ER (supplemental Fig. S8, available at www.jneurosci.org as supplemental material). Our $v p s-4(D N)$ results are also inconsistent with an ER role for USP-46, because in that case, we would expect at least partial suppression of the accumulation of GLR-1 in the VNC of $v p s-4(D N)$ expressing animals by usp-46 mutation. Instead, expression of $v p s-4(D N)$ completely blocks the decrease in GLR-1 observed in usp-46 mutants (Fig. 6). Furthermore, the colocalization of mCherry::USP-46 and the endosomal marker Venus::RAB-5 in the cell body and VNC (supplemental Fig. S8, available at www. jneurosci.org as supplemental material) support a model in which USP-46 functions at an endosomal compartment to prevent the targeting of GLR-1 for degradation. Our analysis of unc-11 AP180;usp-46 double mutants shows that usp-46 loss-offunction mostly prevents the accumulation of GLR-1::GFP caused by unc-11 AP180 mutation (Fig. 5). We propose that USP-46 functions, in part, by acting before clathrin-mediated endocytosis to prevent the degradation of newly synthesized GLR-1 delivered to an internal compartment en route to the plasma membrane. Our data are consistent with a model in which USP-46 functions in a pre-MVB compartment (i.e., endosome) in the cell body and the VNC to prevent the degradation of newly synthesized GLR-1 (Fig. 9). The amount of AMPA receptors at the postsynaptic membrane is likely derived from a recycling pool of receptors undergoing exocytosis, endocytosis, and postendocytic degradation (Ehlers, 2000; Lin et al., 2000; Shepherd and Huganir, 2007), and ubiquitination of GLR-1 provides a signal for its clathrin-mediated endocytosis and subsequent tar- geting to the lysosome (Burbea et al., 2002; Chun et al., 2008). Thus, we propose that the function of USP-46 is to control the amount of GLR-1 in the donor compartment (i.e., endosome) available for delivery to the plasma membrane and that the pool of receptors in this internal compartment may originate from the Golgi or the plasma membrane (Fig. 9).

\section{Role of ubiquitination in membrane protein recycling}

Mono-ubiquitination of membrane proteins at the plasma membrane provides a signal for endocytosis (Hicke and Dunn, 2003). Mono-ubiquitination is also used as a signal to sort and target proteins in the endosome into the MVB/lysosome pathway for degradation (Katzmann et al., 2001; Urbanowski and Piper, 2001). The ubiquitin tag is sufficient to target proteins to the MVB because fusion of ubiquitin to the transferrin receptor, which normally undergoes constitutive recycling to the plasma membrane after endocytosis, prevents its recycling (Raiborg et al., 2002).

DUBs are thought to function in at least two independent steps of the endosome/lysosome pathway. First, DUBs acting at the late endosome promote protein degradation and regenerate free monomeric ubiquitin by deubiquitinating proteins before their destruction in the lysosome. Second, deubiquitination of membrane proteins at endosomes can prevent their degradation in the MVB/lysosome pathway and promote their recycling back to the cell surface (Mukhopadhyay and Riezman, 2007).

Several DUBs have been shown recently to regulate membrane protein recycling in diverse non-neuronal systems. For example, UCH-L3 localizes to endosomes and regulates the surface levels of epithelial $\mathrm{Na}^{+}$channels in kidney cells (Butterworth et al., 2007), USP-10 localizes to endosomes and promotes cystic fibrosis transmembrane-conductance regulator recycling to the epithelial cell surface (Bomberger et al., 2009), USP-20 and USP-33 control recycling of $\beta_{2}$ adrenergic receptors (Berthouze et al., 2009), and both AMSH (associated molecule with the SH3 domain of STAM) and USP-8/UBPY (ubiquitin-specific processing protease $\mathrm{Y}$ ) are endosome-associated DUBs implicated in regulating epidermal growth factor receptor degradation (McCullough et al., 2004; Mizuno et al., 2005; Row et al., 2006). Similarly, reversible ubiquitination of the yeast amino acid permease Gap $1 p$ regulates its trafficking from the plasma membrane to pre-multivesicular endosomes (MVEs) en route to the vacuole for degradation. Interestingly, ubiquitination of newly synthesized Gaplp in the Golgi can directly target it to a pre-MVE compartment in which it is either sorted to the MVE/vacuole for degradation or recycled back to the Golgi for transport to the cell surface (Helliwell et al., 2001; Risinger and Kaiser, 2008). These examples demonstrate that deubiquitination of membrane proteins in the endosome is a widely used mechanism to rescue proteins from degradation and promote their recycling back to the cell surface.

Internalized AMPARs can also be targeted to the lysosome for degradation or recycled back to the plasma membrane in an activity-dependent manner (Ehlers, 2000; Lin et al., 2000; Lee et al., 2004; Park et al., 2004; Wang et al., 2008b). A few molecules have been implicated in regulating AMPAR recycling, including protein kinase A, PKC-interacting protein PICK1, NEEP21 (neuron-enriched endosomal $21 \mathrm{kDa}$ protein), Tmub1/HOPS (hepatocyte odd protein shuttling protein) and UNC-108/Rab2 (Ehlers, 2000; Steiner et al., 2005; Lin and Huganir, 2007; Chun et al., 2008; Yang et al., 2008).

The importance of AMPAR recycling in synaptic plasticity and the central role played by DUBs in the recycling of membrane proteins in general suggest that deubiquitination of internalized 
AMPARs likely contributes to their role in synaptic plasticity. The mechanisms involved in regulating whether postendocytic AMPARs are targeted for lysosomal degradation or sorted into recycling endosomes for delivery back to the postsynaptic membrane are poorly understood. This study shows that the DUB USP-46 regulates GLR-1 abundance at VNC synapses by promoting GLR-1 deubiquitination and preventing its lysosomal degradation. Future studies will be important for identifying the mechanisms that control USP-46 activity and additional components of the ubiquitin signaling system involved in regulating glutamate receptor trafficking and synaptic plasticity.

\section{References}

Arur S, Ohmachi M, Nayak S, Hayes M, Miranda A, Hay A, Golden A, Schedl $T$ (2009) Multiple ERK substrates execute single biological processes in Caenorhabditis elegans germ-line development. Proc Natl Acad Sci U S A 106:4776-4781.

Babst M, Katzmann DJ, Snyder WB, Wendland B, Emr SD (2002) Endosome-associated complex, ESCRT-II, recruits transport machinery for protein sorting at the multivesicular body. Dev Cell 3:283-289.

Berger AJ, Hart AC, Kaplan JM (1998) $\mathrm{G} \alpha_{\mathrm{s}}$-induced neurodegeneration in Caenorhabditis elegans. J Neurosci 18:2871-2880.

Berthouze M, Venkataramanan V, Li Y, Shenoy SK (2009) The deubiquitinases USP33 and USP20 coordinate beta(2) adrenergic receptor recycling and resensitization. EMBO J 28:1684-1696.

Bilodeau PS, Winistorfer SC, Kearney WR, Robertson AD, Piper RC (2003) Vps27-Hse1 and ESCRT-I complexes cooperate to increase efficiency of sorting ubiquitinated proteins at the endosome. J Cell Biol 163:237-243.

Bingol B, Schuman EM (2005) Synaptic protein degradation by the ubiquitin proteasome system. Curr Opin Neurobiol 15:536-541.

Bomberger JM, Barnaby RL, Stanton BA (2009) The deubiquitinating enzyme USP10 regulates the post-endocytic sorting of cystic fibrosis transmembrane conductance regulator in airway epithelial cells. J Biol Chem 284:18778-18789.

Brenner S (1974) The genetics of Caenorhabditis elegans. Genetics 77:71-94.

Brockie PJ, Madsen DM, Zheng Y, Mellem J, Maricq AV (2001a) Differential expression of glutamate receptor subunits in the nervous system of Caenorhabditis elegans and their regulation by the homeodomain protein UNC-42. J Neurosci 21:1510-1522.

Brockie PJ, Mellem JE, Hills T, Madsen DM, Maricq AV (2001b) The C. elegans glutamate receptor subunit NMR-1 is required for slow NMDAactivated currents that regulate reversal frequency during locomotion. Neuron 31:617-630.

Burbea M, Dreier L, Dittman JS, Grunwald ME, Kaplan JM (2002) Ubiquitin and AP180 regulate the abundance of GLR-1 glutamate receptors at postsynaptic elements in C. elegans. Neuron 35:107-120.

Butterworth MB, Edinger RS, Ovaa H, Burg D, Johnson JP, Frizzell RA (2007) The deubiquitinating enzyme UCH-L3 regulates the apical membrane recycling of the epithelial sodium channel. J Biol Chem 282:37885-37893.

Cartier AE, Djakovic SN, Salehi A, Wilson SM, Masliah E, Patrick GN (2009) Regulation of synaptic structure by ubiquitin C-terminal hydrolase L1. J Neurosci 29:7857-7868.

Ceron J, Rual JF, Chandra A, Dupuy D, Vidal M, van den Heuvel S (2007) Large-scale RNAi screens identify novel genes that interact with the $C$. elegans retinoblastoma pathway as well as splicing-related components with synMuv B activity. BMC Dev Biol 7:30.

Cheeseman IM, Desai A (2005) A combined approach for the localization and tandem affinity purification of protein complexes from metazoans. Sci STKE 2005:pl1.

Chen F, Sugiura Y, Myers KG, Liu Y, Lin W (2010) Ubiquitin carboxyl-terminal hydrolase L1 is required for maintaining the structure and function of the neuromuscular junction. Proc Natl Acad Sci U S A 107:1636-1641.

Chen H, Polo S, Di Fiore PP, De Camilli PV (2003) Rapid Ca ${ }^{2+}$-dependent decrease of protein ubiquitination at synapses. Proc Natl Acad Sci U S A 100:14908-14913.

Chun DK, McEwen JM, Burbea M, Kaplan JM (2008) UNC-108/Rab2 regulates postendocytic trafficking in Caenorhabditis elegans. Mol Biol Cell 19:2682-2695.

Cohn MA, Kee Y, Haas W, Gygi SP, D'Andrea AD (2009) UAF1 is a subunit of multiple deubiquitinating enzyme complexes. J Biol Chem 284:5343-5351.

Colledge M, Snyder EM, Crozier RA, Soderling JA, Jin Y, Langeberg LK, Lu H, Bear MF, Scott JD (2003) Ubiquitination regulates PSD-95 degradation and AMPA receptor surface expression. Neuron 40:595-607.

DiAntonio A, Haghighi AP, Portman SL, Lee JD, Amaranto AM, Goodman CS (2001) Ubiquitination-dependent mechanisms regulate synaptic growth and function. Nature 412:449-452.

Dreier L, Burbea M, Kaplan JM (2005) LIN-23-mediated degradation of beta-catenin regulates the abundance of GLR-1 glutamate receptors in the ventral nerve cord of C. elegans. Neuron 46:51-64.

Ehlers MD (2000) Reinsertion or degradation of AMPA receptors determined by activity-dependent endocytic sorting. Neuron 28:511-525.

Emtage L, Chang H, Tiver R, Rongo C (2009) MAGI-1 modulates AMPA receptor synaptic localization and behavioral plasticity in response to prior experience. PLoS One 4:e4613.

Gong B, Cao Z, Zheng P, Vitolo OV, Liu S, Staniszewski A, Moolman D, Zhang H, Shelanski M, Arancio O (2006) Ubiquitin hydrolase Uch-L1 rescues beta-amyloid-induced decreases in synaptic function and contextual memory. Cell 126:775-788.

Grunwald ME, Kaplan JM (2003) Mutations in the ligand-binding and pore domains control exit of glutamate receptors from the endoplasmic reticulum in C. elegans. Neuropharmacology 45:768-776.

Hansen-Hagge TE, Janssen JW, Hameister H, Papa FR, Zechner U, Seriu T, Jauch A, Becke D, Hochstrasser M, Bartram CR (1998) An evolutionarily conserved gene on human chromosome 5q33-q34, UBH1, encodes a novel deubiquitinating enzyme. Genomics 49:411-418.

Hart AC, Sims S, Kaplan JM (1995) Synaptic code for sensory modalities revealed by C. elegans GLR-1 glutamate receptor. Nature 378:82-85.

Hegde AN, Inokuchi K, Pei W, Casadio A, Ghirardi M, Chain DG, Martin KC, Kandel ER, Schwartz JH (1997) Ubiquitin C-terminal hydrolase is an immediate-early gene essential for long-term facilitation in Aplysia. Cell 89:115-126.

Helliwell SB, Losko S, Kaiser CA (2001) Components of a ubiquitin ligase complex specify polyubiquitination and intracellular trafficking of the general amino acid permease. J Cell Biol 153:649-662.

Hicke L, Dunn R (2003) Regulation of membrane protein transport by ubiquitin and ubiquitin-binding proteins. Annu Rev Cell Dev Biol 19:141-172.

Jiang YH, Armstrong D, Albrecht U, Atkins CM, Noebels JL, Eichele G, Sweatt JD, Beaudet AL (1998) Mutation of the Angelman ubiquitin ligase in mice causes increased cytoplasmic $\mathrm{p} 53$ and deficits of contextual learning and long-term potentiation. Neuron 21:799-811.

Juo P, Kaplan JM (2004) The anaphase-promoting complex regulates the abundance of GLR-1 glutamate receptors in the ventral nerve cord of $C$. elegans. Curr Biol 14:2057-2062.

Juo P, Harbaugh T, Garriga G, Kaplan JM (2007) CDK-5 regulates the abundance of GLR-1 glutamate receptors in the ventral cord of Caenorhabditis elegans. Mol Biol Cell 18:3883-3893.

Jurd R, Thornton C, Wang J, Luong K, Phamluong K, Kharazia V, Gibb SL, Ron D (2008) Mind bomb-2 is an E3 ligase that ubiquitinates the $\mathrm{N}$-methyl-D-aspartate receptor NR2B subunit in a phosphorylationdependent manner. J Biol Chem 283:301-310.

Kahn NW, Rea SL, Moyle S, Kell A, Johnson TE (2008) Proteasomal dysfunction activates the transcription factor $\mathrm{SKN}-1$ and produces a selective oxidative-stress response in Caenorhabditis elegans. Biochem J 409:205-213.

Kamath RS, Fraser AG, Dong Y, Poulin G, Durbin R, Gotta M, Kanapin A, Le Bot N, Moreno S, Sohrmann M, Welchman DP, Zipperlen P, Ahringer J (2003) Systematic functional analysis of the Caenorhabditis elegans genome using RNAi. Nature 421:231-237.

Kaplan JM, Horvitz HR (1993) A dual mechanosensory and chemosensory neuron in Caenorhabditis elegans. Proc Natl Acad Sci USA 90:2227-2231.

Kato A, Rouach N, Nicoll RA, Bredt DS (2005) Activity-dependent NMDA receptor degradation mediated by retrotranslocation and ubiquitination. Proc Natl Acad Sci U S A 102:5600-5605.

Katzmann DJ, Babst M, Emr SD (2001) Ubiquitin-dependent sorting into the multivesicular body pathway requires the function of a conserved endosomal protein sorting complex, ESCRT-I. Cell 106:145-155.

Katzmann DJ, Odorizzi G, Emr SD (2002) Receptor downregulation and multivesicular-body sorting. Nat Rev Mol Cell Biol 3:893-905. 
Kee Y, Yang K, Cohn MA, Haas W, Gygi SP, D’Andrea AD (2010) WDR20 regulates activity of the USP $12 \times$ UAF1 deubiquitinating enzyme complex. J Biol Chem 285:11252-11257.

Kohda K, Wang Y, Yuzaki M (2000) Mutation of a glutamate receptor motif reveals its role in gating and delta2 receptor channel properties. Nat Neurosci 3:315-322.

Lee SH, Simonetta A, Sheng M (2004) Subunit rules governing the sorting of internalized AMPA receptors in hippocampal neurons. Neuron 43:221-236.

Lin DT, Huganir RL (2007) PICK1 and phosphorylation of the glutamate receptor 2 (GluR2) AMPA receptor subunit regulates GluR2 recycling after NMDA receptor-induced internalization. J Neurosci 27:13903-13908.

Lin JW, Ju W, Foster K, Lee SH, Ahmadian G, Wyszynski M, Wang YT, Sheng M (2000) Distinct molecular mechanisms and divergent endocytotic pathways of AMPA receptor internalization. Nat Neurosci 3:1282-1290.

Maricq AV, Peckol E, Driscoll M, Bargmann CI (1995) Mechanosensory signalling in C. elegans mediated by the GLR-1 glutamate receptor. Nature 378:78-81.

McCullough J, Clague MJ, Urbé S (2004) AMSH is an endosome-associated ubiquitin isopeptidase. J Cell Biol 166:487-492.

Milojevic T, Reiterer V, Stefan E, Korkhov VM, Dorostkar MM, Ducza E, Ogris E, Boehm S, Freissmuth M, Nanoff C (2006) The ubiquitinspecific protease Usp4 regulates the cell surface level of the A2A receptor. Mol Pharmacol 69:1083-1094.

Mizuno E, Iura T, Mukai A, Yoshimori T, Kitamura N, Komada M (2005) Regulation of epidermal growth factor receptor down-regulation by UBPY-mediated deubiquitination at endosomes. Mol Biol Cell 16: 5163-5174.

Mu Y, Otsuka T, Horton AC, Scott DB, Ehlers MD (2003) Activitydependent mRNA splicing controls ER export and synaptic delivery of NMDA receptors. Neuron 40:581-594.

Mukhopadhyay D, Riezman H (2007) Proteasome-independent functions of ubiquitin in endocytosis and signaling. Science 315:201-205.

Nijman SM, Luna-Vargas MP, Velds A, Brummelkamp TR, Dirac AM, Sixma TK, Bernards R (2005) A genomic and functional inventory of deubiquitinating enzymes. Cell 123:773-786.

Nonet ML, Holgado AM, Brewer F, Serpe CJ, Norbeck BA, Holleran J, Wei L, Hartwieg E, Jorgensen EM, Alfonso A (1999) UNC-11, a Caenorhabditis elegans AP180 homologue, regulates the size and protein composition of synaptic vesicles. Mol Biol Cell 10:2343-2360.

Ovaa H, Kessler BM, Rolén U, Galardy PJ, Ploegh HL, Masucci MG (2004) Activity-based ubiquitin-specific protease (USP) profiling of virusinfected and malignant human cells. Proc Natl Acad Sci U S A 101: 2253-2258.

Park EC, Glodowski DR, Rongo C (2009) The ubiquitin ligase RPM-1 and the p38 MAPK PMK-3 regulate AMPA receptor trafficking. PLoS ONE 4:e4284.

Park M, Penick EC, Edwards JG, Kauer JA, Ehlers MD (2004) Recycling endosomes supply AMPA receptors for LTP. Science 305:1972-1975.

Patrick GN, Bingol B, Weld HA, Schuman EM (2003) Ubiquitin-mediated proteasome activity is required for agonist-induced endocytosis of GluRs. Curr Biol 13:2073-2081.

Quesada V, Díaz-Perales A, Gutiérrez-Fernández A, Garabaya C, Cal S, López-Otín C (2004) Cloning and enzymatic analysis of 22 novel human ubiquitin-specific proteases. Biochem Biophys Res Commun 314:54-62.

Raasi S, Wolf DH (2007) Ubiquitin receptors and ERAD: a network of pathways to the proteasome. Semin Cell Dev Biol 18:780-791.

Raiborg C, Bache KG, Gillooly DJ, Madshus IH, Stang E, Stenmark H (2002) Hrs sorts ubiquitinated proteins into clathrin-coated microdomains of early endosomes. Nat Cell Biol 4:394-398.

Risinger AL, Kaiser CA (2008) Different ubiquitin signals act at the Golgi and plasma membrane to direct GAP1 trafficking. Mol Biol Cell 19:2962-2972.

Rongo C, Whitfield CW, Rodal A, Kim SK, Kaplan JM (1998) LIN-10 is a shared component of the polarized protein localization pathways in neurons and epithelia. Cell 94:751-759.

Row PE, Prior IA, McCullough J, Clague MJ, Urbé S (2006) The ubiquitin isopeptidase UBPY regulates endosomal ubiquitin dynamics and is essential for receptor down-regulation. J Biol Chem 281:12618-12624.
Rual JF, Ceron J, Koreth J, Hao T, Nicot AS, Hirozane-Kishikawa T, Vandenhaute J, Orkin SH, Hill DE, van den Heuvel S, Vidal M (2004) Toward improving Caenorhabditis elegans phenome mapping with an ORFeomebased RNAi library. Genome Res 14:2162-2168.

Schaefer H, Rongo C (2006) KEL-8 is a substrate receptor for CUL3dependent ubiquitin ligase that regulates synaptic glutamate receptor turnover. Mol Biol Cell 17:1250-1260.

Shepherd JD, Huganir RL (2007) The cell biology of synaptic plasticity: AMPA receptor trafficking. Annu Rev Cell Dev Biol 23:613-643.

Sieburth D, Ch'ng Q, Dybbs M, Tavazoie M, Kennedy S, Wang D, Dupuy D, Rual JF, Hill DE, Vidal M, Ruvkun G, Kaplan JM (2005) Systematic analysis of genes required for synapse structure and function. Nature 436:510-517.

Song L, Rape M (2008) Reverse the curse: the role of deubiquitination in cell cycle control. Curr Opin Cell Biol 20:156-163.

Sowa ME, Bennett EJ, Gygi SP, Harper JW (2009) Defining the human deubiquitinating enzyme interaction landscape. Cell 138:389-403.

Speese SD, Trotta N, Rodesch CK, Aravamudan B, Broadie K (2003) The ubiquitin proteasome system acutely regulates presynaptic protein turnover and synaptic efficacy. Curr Biol 13:899-910.

Steiner P, Alberi S, Kulangara K, Yersin A, Sarria JC, Regulier E, Kasas S, Dietler G, Muller D, Catsicas S, Hirling H (2005) Interactions between NEEP21, GRIP1 and GluR2 regulate sorting and recycling of the glutamate receptor subunit GluR2. EMBO J 24:2873-2884.

Tomida S, Mamiya T, Sakamaki H, Miura M, Aosaki T, Masuda M, Niwa M, Kameyama T, Kobayashi J, Iwaki Y, Imai S, Ishikawa A, Abe K, Yoshimura T, Nabeshima T, Ebihara S (2009) Usp46 is a quantitative trait gene regulating mouse immobile behavior in the tail suspension and forced swimming tests. Nat Genet 41:688-695.

Tomita S, Nicoll RA, Bredt DS (2001) PDZ protein interactions regulating glutamate receptor function and plasticity. J Cell Biol 153:F19-F24.

Urbanowski JL, Piper RC (2001) Ubiquitin sorts proteins into the intralumenal degradative compartment of the late-endosome/vacuole. Traffic 2:622-630.

van Roessel P, Elliott DA, Robinson IM, Prokop A, Brand AH (2004) Independent regulation of synaptic size and activity by the anaphasepromoting complex. Cell 119:707-718.

Wang D, Kennedy S, Conte D Jr, Kim JK, Gabel HW, Kamath RS, Mello CC, Ruvkun G (2005) Somatic misexpression of germline P granules and enhanced RNA interference in retinoblastoma pathway mutants. Nature 436:593-597.

Wang R, Walker CS, Brockie PJ, Francis MM, Mellem JE, Madsen DM, Maricq AV (2008a) Evolutionary conserved role for TARPs in the gating of glutamate receptors and tuning of synaptic function. Neuron 59:997-1008.

Wang Z, Edwards JG, Riley N, Provance DW Jr, Karcher R, Li XD, Davison IG, Ikebe M, Mercer JA, Kauer JA, Ehlers MD (2008b) Myosin Vb mobilizes recycling endosomes and AMPA receptors for postsynaptic plasticity. Cell 135:535-548.

Wilson SM, Bhattacharyya B, Rachel RA, Coppola V, Tessarollo L, Householder DB, Fletcher CF, Miller RJ, Copeland NG, Jenkins NA (2002) Synaptic defects in ataxia mice result from a mutation in Usp14, encoding a ubiquitin-specific protease. Nat Genet 32:420-425.

Yang H, Takagi H, Konishi Y, Ageta H, Ikegami K, Yao I, Sato S, Hatanaka K, Inokuchi K, Seog DH, Setou M (2008) Transmembrane and ubiquitinlike domain-containing protein 1 (Tmub1/HOPS) facilitates surface expression of GluR2-containing AMPA receptors. PLoS ONE 3:e2809.

Yi JJ, Ehlers MD (2007) Emerging roles for ubiquitin and protein degradation in neuronal function. Pharmacol Rev 59:14-39.

Zhao Y, Hegde AN, Martin KC (2003) The ubiquitin proteasome system functions as an inhibitory constraint on synaptic strengthening. Curr Biol 13:887-898.

Zheng Y, Brockie PJ, Mellem JE, Madsen DM, Maricq AV (1999) Neuronal control of locomotion in C. elegans is modified by a dominant mutation in the GLR-1 ionotropic glutamate receptor. Neuron 24:347-361.

Zheng Y, Mellem JE, Brockie PJ, Madsen DM, Maricq AV (2004) SOL-1 is a CUB-domain protein required for GLR-1 glutamate receptor function in C. elegans. Nature 427:451-457. 